Revue des patrimoines

\title{
Les édifices néogothiques parisiens et leurs verrières : églises et chapelles catholiques
}

\section{Martine Callias Bey}

\section{OpenEdition}

\section{Journals}

Édition électronique

URL : http://journals.openedition.org/insitu/7052

DOI : 10.4000/insitu.7052

ISSN : 1630-7305

\section{Éditeur}

Ministère de la culture

Référence électronique

Martine Callias Bey, «Les édifices néogothiques parisiens et leurs verrières : églises et chapelles catholiques », In Situ [En ligne], 11 | 2009, mis en ligne le 24 avril 2012, consulté le 01 mai 2019. URL http://journals.openedition.org/insitu/7052 ; DOI : 10.4000/insitu.7052

Ce document a été généré automatiquement le 1 mai 2019.

\section{(c) (i) (9)}

In Situ Revues des patrimoines est mis à disposition selon les termes de la licence Creative Commons Attribution - Pas d'Utilisation Commerciale - Pas de Modification 4.0 International. 


\title{
Les édifices néogothiques parisiens et leurs verrières : églises et chapelles catholiques
}

\author{
Martine Callias Bey
}

Figure 1

[Image non convertie]

Saint Vincent-de-Paul, sainte Geneviève, saint Louis, sainte Clotilde, saint Roch, croisillon sud de SaintBernard-de-La-Chapelle, par Johann-Caspard-Jules Gsell et Émile Laurent, 1863

(C) Martin Argyroglo Callias Bey, 2008

2 Cette étude est le premier état d'une recherche sur les vitraux du XIX ${ }^{\mathrm{e}}$ siècle (1816-1914) situés dans les lieux de culte chrétiens de la ville de Paris: églises, chapelles privées conventuelles, hospitalières, militaires, chapelles de l'enseignement privé, temples protestants et églises orthodoxes. Cet inventaire, commencé en 2005, concernera environ 200 sites. L'intérêt de ce programme de recherche est double: d'une part, accroître la connaissance du patrimoine religieux de la capitale et inciter à le mettre en valeur, d'autre part, compléter le volume du Recensement des vitraux anciens de la France, publié en 1978 sous les auspices du Corpus Vitrearum de la France et consacré aux vitraux de Paris notamment, mais limité chronologiquement à la Révolution. La publication de ce nouveau recensement est prévue pour l'année 2010 dans une collection du Corpus Vitrearum français, sous une forme qui reste à définir, puisqu'elle serait la première d'une série consacrée exclusivement aux vitraux du XIX ${ }^{\mathrm{e}}$ siècle.

3 L'objet de cet article est la présentation des édifices catholiques parisiens, construits en style néogothique, et de leurs verrières ${ }^{1}$. Le corpus étudié comprend 5 églises paroissiales, 16 chapelles de congrégations ou anciennes chapelles devenues paroisses, la chapelle d'un hôtel particulier, deux bâtiments annexes, une chapelle de palais, une chapelle des catéchismes et une chapelle de patronage. Cet inventaire réserve des surprises, dont la moindre n'est pas l'importance de certains de ces édifices, comparables à de véritables 
églises, le plus souvent cachés derrière les murs des couvents parisiens et complètement ignorés. Il faut donc pousser les portes, même si l'on rencontre parfois un peu de résistance... C'est le but affiché, parmi d'autres, par les "Balades du patrimoine", organisées par la Mairie de Paris, consultables sur le site http://www.paris.fr/loisirs/ paris-loisirs/p9626.

4 L'urgence d'un inventaire est un faible mot, beaucoup de vitraux du XIX ${ }^{\mathrm{e}}$ s. ayant déjà disparu, faute d'avoir été réparés à temps ou plus grave encore, du fait de la démolition des chapelles elles-mêmes ${ }^{2}$ ou du réaménagement de certaines d'entre elles ${ }^{3}$. L'intérêt porté aux œuvres d'art religieuses du XIX ${ }^{e}$ siècle remonte aux années 1980, avec un temps d'avance pour Jean Taralon, inspecteur général des Monuments historiques, qui leur consacra un chapitre dans le Vitrail français paru en $1958^{4}$. Bruno Foucart et Jean-Michel Leniaud ont contribué à faire émerger le XIX ${ }^{e}$ siècle depuis une quarantaine d'années ${ }^{5}$. Puis ce sont les travaux de Catherine Brisac ${ }^{6}$, de Chantal Bouchon et la mise au point d'un répertoire des peintres verriers du $\mathrm{XIX}^{\mathrm{e}} \mathrm{s}$. par la cellule Vitrail de l'Inventaire Général (725 noms $)^{7}$, qui ont pu inciter le public à s'intéresser à cette période. L'exposition sur Viollet-le-Duc en 1980 et le colloque international qui l'accompagnait ont relayé cet intérêt naissant pour l'art officiel et religieux du XIX ${ }^{e}{ }^{8}{ }^{8}$. Pierre-Marie Auzas, inspecteur général des Monuments historiques, créa l'Association pour l'étude du XIXe siècle français en 1984 pour notamment « faire connaître et défendre les vitraux du XIX siècle car ils sont trop souvent menacés ». Deux rapports s'ensuivirent au ministère de la Culture, l'un sur l'étude et la conservation des vitraux du XIX ${ }^{e}$ s. et du début du XX ${ }^{e}$ s. en Île-de-France, daté de janvier $1985^{\circ}$, suivi d'une demande de statuer sur des critères de protection, l'autre étude confiée en 1987 à Mme Vanina Costa ${ }^{10}$. À signaler aussi les études menées par la section "vitrail du XIX ${ }^{e}$ s.» au sein du GRIMCO ${ }^{11}$, sous la responsabilité de Catherine Brisac. Enfin parurent de nombreuses études générales et régionales, sur Paris et la région parisienne en particulier : sur Sainte-Clotilde par Catherine Brisac et Chantal Bouchon ${ }^{12}$, sur la renaissance du vitrail et la manufacture de Sèvres par Nicole Blondel et Patrick Bracco ${ }^{13}$; s'y ajoutèrent les articles d'Hervé Cabezas ${ }^{14}$, de Françoise Gatouillat ${ }^{15}$ et de Jean-François Luneau ${ }^{16}$, ses travaux universitaires et ceux d'Élisabeth Pillet ${ }^{17}$, parus et à paraître, jusqu'à la synthèse de Laurence de Finance Un patrimoine de lumière, paru en 2003, qui fait référence en la matière ${ }^{18}$. Malgré toutes ces études, ce patrimoine demeure encore trop méconnu, tant il est étendu, et par là même menacé.

Le manque d'archives à propos de la fondation des chapelles et de leur décor se fait cruellement sentir ${ }^{19}$. L'on trouve à cela plusieurs causes, à savoir les baisses d'effectifs dans les communautés, les regroupements et les bouleversements des locaux qui ont entrainé de nombreuses fermetures de couvents et la mise en péril des archives de ces communautés; malgré la publication en 1975 d'un Guide des sources de l'histoire des congrégations féminines françaises de vie active ${ }^{20}$, qui a sensibilisé les religieux au problème, la consultation de ces archives reste une difficulté; celles-ci sont souvent regroupées désormais dans les maisons centrales, qui permettent rarement l'accès à leur fonds historiques.

6 Cette étude concerne les édifices néogothiques parisiens suivants, dont certains sont étudiés sur le site http://www.paris.fr/loisirs/paris-loisirs/p9626 (Le style néogothique et Vitraux parisiens) :

- $1^{\mathrm{er}} \operatorname{arr}^{\mathrm{t}}$. : Beffroi de Saint-Germain-l'Auxerrois ${ }^{21}$

- Chapelle du Conseil d'État, www.conseil-etat.fr

- $4^{\mathrm{ème}}$ arr $^{\mathrm{t}}$ : Sacristie de Notre-Dame-de-Paris ${ }^{22}$ 
- $5^{\text {ème }}$ arr $^{\mathrm{t}}$. : Notre-Dame du Liban (ancienne chapelle), www.notredameduliban.org

- $6^{\text {ème }}$ arr $^{\mathrm{t}}$. : Chapelle Notre-Dame-des-Anges ${ }^{23}$, www.forum104.info/ChapelleNDA.html

- Chapelle Notre-Dame-du-Bon-Secours

- Chapelle de l'Accueil-Louise-de-Marillac

- Chapelle Saint-Ignace, www.stignace.net

- $7^{\text {ème }}$ arr $^{\mathrm{t}}$ : Chapelle de l'ancien hôtel de Bourbon-Condéé

- Sainte-Clotilde ${ }^{25}$, www.sainte-clotilde.com et www.paris.fr/portail/Culture

- Chapelle de Jésus-Enfant (catéchismes)

- sème $^{\text {arrt }}{ }^{t}$ : Saint-André de l'Europe (ancienne chapelle), www.st-andre-europe.org

- Chapelle des Sœurs du Bon-Secours-de-Troyes

- $9^{\text {ème }} \operatorname{arr}^{\mathrm{t}}$. : Saint-Eugène ${ }^{26}$, www.saint-eugene.net

- $10^{\text {ème }} \operatorname{arr}^{\mathrm{t}}$. : Chapelle des Jeunes de Saint-Vincent-de-Paul (patronage)

- Saint-Joseph-Artisan (ancienne chapelle), pagesperso-orange.fr/sjoart

- $13^{\text {ème }}$ arr $^{\mathrm{t}}$ : Sainte-Rosalie (ancienne chapelle), www.sainte-rosalie.org

- Saint-Hippolyte, www.saint-hippolyte.net

- $14^{\text {ème }} \operatorname{arr}^{\mathrm{t}}$. : Chapelle Sainte-Jeanne-d'Arc, www.fmm.org

- Chapelle des Sœurs de Saint-Joseph-de-Cluny

- $15^{\text {ème }}$ arr $^{\mathrm{t}}$.: Chapelle de l'Orphelinat-Saint-Charles

- Chapelle Sainte-Marie-de-la-Famille

- $16^{\text {ème }}$ arr $^{\mathrm{t}}$. : Chapelle Notre-Dame-du-Saint-Sacrement

- Chapelle Sainte-Thérèse-de-l'Enfant-Jésus (Orphelins d'Auteuil)

- $18^{\text {ème }}$ arr $^{\text {t. }}$ : Saint-Bernard-de-la-Chapelle, www.lagouttedor.net

- Notre-Dame-du-Bon-Conseil, paroisse.ndbc.free.fr

- $20^{\text {ème }}$ arr $^{\mathrm{t}}$. : Saint-Jean-Baptiste-de-Belleville, http://www.sjbb.org.

\section{Le contexte concordataire et l'« explosion » congrégationiste}

7 Après la Révolution, Paris et la région parisienne, spécialement atteints par l'indifférence religieuse, connaissent une véritable chute de la pratique cultuelle. Signé le 16 juillet 1801 entre Bonaparte et le cardinal Consalvi, représentant du pape Pie VII, le Concordat institue la liberté des cultes mais renforce l'autorité spirituelle du pape sur l'Église de France ; ainsi se profilent les débuts d'un ultramontanisme qui s'imposera au milieu du siècle. La loi concordataire rétablit le rôle des fabriques paroissiales comme responsables des édifices cultuels et de leur entretien, de la reconstitution de leur décor et de leur mobilier ; les dons des fidèles et les droits perçus à l'occasion des cérémonies religieuses sont les principales sources de revenus. Le Concordat a placé l'Église de France dans la dépendance de l'état, qui met les lieux de culte à la disposition du clergé.

Figure 2

8 [Image non convertie]

Figures de L'Église, verrière du chœur de Saint-André-de-l'Europe, par Georges-Claudius Lavergne, vers 1897

(c) Martin Argyroglo Callias Bey, 2008

En réaction à cette collusion Église/État, un tournant s'amorce pendant le Second Empire. Rome impose de plus en plus la liturgie romaine, devenue obligatoire en 1857 à Paris sous 
l'évêché de Mgr Sibour. Cette primauté de l'autorité du pape sur le catholicisme français est renforcée par la proclamation du dogme de l'Immaculée Conception le 8 décembre $1854^{27}$, puis par la publication le 8 décembre 1864 par Pie IX du Syllabus (catalogue des «erreurs» de la pensée moderne) et enfin par la proclamation des dogmes de l'infaillibilité pontificale et de la primauté universelle de droit divin du pape, le 18 juillet 1870, en présence de tout l'épiscopat français réuni au concile Vatican I en $1869^{28}$. Ces trois étapes contribuent au triomphe de l'ultramontanisme, réaffirmé en 1905, au détriment des associations cultuelles, des ordres et des congrégations. La verrière de Saint-André-de-l'Europe est un véritable manifeste ultramontain, mis en œuvre par Georges-Claudius Lavergne, artiste héritier d'une forte tradition religieuse.

L'enseignement dispensé aux futurs prêtres au sein de l'École des Carmes fondée en 1845 par Mgr Affre, comprenait une formation à l'histoire de l'art ; celle-ci va se développer dans les premières facultés catholiques ouvertes en $1875^{29}$. Le thème récurrent de la République menacée par «les congrégations et les manifestations ostentatoires du catholicisme » entraîne, entre 1899 et 1904, un profond anticléricalisme au sein de l'État, qui prélude à la loi de Séparation du 9 décembre 1905.

\section{Le « temps des congrégations »}

Figure 3

11 [Image non convertie]

L'Ordre de Sainte-Marie-de-la-Famille consacré par le cardinal et l'archevêque de Paris (Mgr de la Vergne ?), chapelle Sainte-Marie-de-la-Famille, par la Société artistique de Peinture sur verre, 1900 Phot. Jean-Bernard Vialles, 2008. @ Région île-de-France-Inventaire général / ADAGP

12 En 1789, Paris comptait 199 communautés religieuses, réparties essentiellement dans les quartiers sud et ouest de la capitale, avec déjà plus de femmes que d'hommes; parmi celles qui furent supprimées en 1790 et en 1792, beaucoup se reformèrent sous le Consulat ${ }^{30}$. Depuis la Révolution, les religieuses avaient acquis une certaine indépendance, puisqu'elles n'étaient liées désormais que par des vœux simples qui leur permettaient d'hériter et de conserver leurs biens. Bonaparte avait accepté leur existence en distinguant celles qui étaient " autorisées ", donc pouvant posséder des biens (la « mainmorte»), de celles qui n'étaient que tolérées. Sous la Restauration (1814-1848), les congrégations acquirent un statut: alors que les congrégations masculines devaient être " autorisées » par une loi, une simple décision administrative suffisait pour la création des congrégations féminines. Leur statut fut alors organisé par quatre lois (en 1809, le 2 janvier 1817, le 24 mai 1825 et en 1852) ${ }^{31}$. Les autorisations furent massivement accordées jusqu'en 1830, date à laquelle la moitié des 3400 autorisations du XIX ${ }^{e}$ siècle avaient déjà été accordées ${ }^{32}$. Sous la Restauration et pendant le Second Empire, une nouvelle législation favorisa les congrégations féminines. Les ordres autorisés, particulièrement les Sœurs de charité, reçurent des subventions de l'État dès leur premier établissement.

13 À partir des années 1830, devant l'étendue des problèmes liés à l'extrême dénuement d'une grande partie de la population, de nombreuses œuvres charitables se développèrent pour suppléer à la carence de l'État. D'initiative ecclésiastique ou laïque, elles étaient presque toujours le fait d'une communauté de religieux ou plus souvent de religieuses. L'épidémie de choléra, qui fit 12000 morts à Paris au printemps 1832, causa une aggravation de la situation sociale, et le développement d'une religiosité un peu 
superstitieuse, dont témoigne la frappe de la Médaille miraculeuse, après l'apparition de la Vierge à Catherine Labouré dans la chapelle des Filles de la Charité rue du Bac en 1830. 400 nouvelles congrégations furent fondées entre 1796 et 1880 (dont 300 congrégations féminines) ${ }^{33}$. La multiplication des chapelles à Paris s'explique par l'éclosion des ordres hospitaliers, enseignants, missionnaires, des maisons mères, sans parler du retour des ordres religieux anciens : les Jésuites en 1814 (6000 en 1850), les Bénédictins en 1837, les Dominicains en 1843, les Franciscains et les Carmes. Cet élan fut largement soutenu par des dons et des legs privés ${ }^{34}$.

14 Les congrégations féminines liées à une famille religieuse née tantôt au Moyen Âge (Clarisses, Bénédictines, Dominicaines, Augustines), tantôt pendant la Contre-Réforme (Ursulines, Visitandines), étaient animées d'un essor exceptionnel et répondaient toutes à une demande sociale : deux tiers d'entre elles étaient enseignantes (privé ou public), un quart soignantes à domicile ou dans les hôpitaux.

\section{Figure 4}

15 [Image non convertie]

Sœur Rosalie Rendu, verrière d'axe de Sainte-Rosalie (détail), par Édouard-Amédée Didron, 1872

Phot. Martine Callias Bey, 2008. (C) Centre André Chastel

L'on doit aux ordres suivants la construction de chapelles néogothiques à Paris : les Sœurs de Saint-Joseph-de-Cluny, ordre missionnaire hospitalier et enseignant, fondé par la bienheureuse Anne-Marie Jahouvey vers $1816^{35}$, les Sœurs Servantes du Saint-Sacrement, instituées par le Père Eymard vers 1900, les Filles de la Charité, soignantes et missionnaires, fondées en 1633 par Louise de Marillac et saint Vincent de Paul, sous la tutelle des Lazaristes ${ }^{36}$ (fig. $\mathbf{n}^{\circ}$ 4), les Sœurs du Bon-Secours, missionnaires établies en 1824 par Joséphine Potel et Mgr de Quélen, très actives lors du choléra qui sévit à Paris en 1832, les Sœurs de Notre-Dame-des-Anges, congrégation créée en 1854 par le Père Bayle ${ }^{37}$, les Sœurs de Sainte-Marie-de-la-Famille, dont la maison de santé accueillit une clientèle bourgeoise rue Blomet à partir de 1888, les Sœurs du Bon-Secours-de-Troyes et les Franciscaines missionnaires de Marie, fondées en 1877 par Marie de la Passion (Hélène de (happotin) ${ }^{38}$.

17 Les Missions extérieures se développèrent vers les Mondes nouveaux, États-Unis, Amérique du Sud, Australie, Afrique un peu plus tard... Le romantisme missionnaire reçut sous la Restauration l'appui du gouvernement français et les congrégations missionnaires se multiplièrent depuis la Révolution de 1830, précédant l'expansion coloniale. La France fut le premier pays missionnaire catholique du XIX ${ }^{e}$ siècle.

18 La plupart des ordres masculins étaient enseignants (Marianistes fondés en 1817 par Guillaume Joseph Chaminade, Marianistes Salésiens de Don Bosco fondés en 1817 par saint Jean Bosco, Maristes des écoles fondés par saint Marcellin Champagnat en 1817, Frères des écoles chrétiennes, fondés par saint Jean-Baptiste de la Salle en 1684, Rédemptoristes héritiers d'Alphonse de Liguori, etc.). Dès 1802, l'Église s'était attelée à l'éducation des jeunes ${ }^{39}$, notamment par l'ouverture de patronages ${ }^{40}$ et d'écoles chrétiennes confiées aux Frères en 1822, et par la prédication de missions (1000 à 1500 sous la Restauration). Le combat pour la liberté de l'enseignement fut mené sous l'impulsion de Mgr Dupanloup; trois lois définirent désormais l'enseignement catholique : loi Guizot de 1833 pour l'enseignement primaire (confirmation de la place de 
la religion dans la pédagogie scolaire), loi Falloux en 1850 pour l'enseignement secondaire, loi Laboulaye pour l'enseignement supérieur en 1875.

Figure 5

[Image non convertie]

Enfance du Christ, chœur de la chapelle Notre-Dame-des-Anges, par Joseph Villiet, 1866.

Phot. Philippe Fortin, 2006. (c) Inventaire général ADAGP

Quelques chapelles néogothiques témoignent de cet élan: l'ancienne chapelle des Lazaristes (aujourd'hui Sainte-Rosalie), ordre fondé par saint Vincent de Paul, celle des Frères des écoles chrétiennes (Saint-Joseph-Artisan), l'ancienne chapelle de l'École Sainte-Geneviève des Jésuites (Notre-Dame du Liban), la chapelle de la Compagnie de Jésus (Saint-Ignace) ${ }^{41}$, celle des Oblats de Marie Immaculée, ordre missionnaire fondé par Mgr de Mazenod en 1816, l'actuelle église Saint-André de l'Europe, la chapelle NotreDame-des-Anges des Maristes missionnaires, fondés en 1816 par le Père Colin (fig. $\mathbf{n}^{\circ}$ 5). Le mouvement de «re-christianisation » culmina vers 1860-1870, malgré les défenseurs de l'école républicaine qui obtinrent gain de cause après la Commune de Paris. Jusqu'aux lois Ferry (1882) et Goblet (1886), l'Église avait en charge la moitié du primaire, du secondaire et du supérieur.

21 Un rapport daté de 1878 sur les communautés religieuses, autorisées ou non, suivi d'un recensement au 1er janvier 1901, aboutit à une législation « anti-congrégationiste ». Une politique peu favorable à l'Église conduisit en 1880 aux premières expulsions, d'une part de congrégations hospitalières et enseignantes, d'autre part de congrégations d'hommes non autorisées, dont les Jésuites déjà interdits en $1828^{42}$. La mission de soigner ayant été retirée aux congrégations hospitalières, une baisse de qualité des soins et un surcoût pour la nation s'ensuivirent; les religieuses qui n'avaient pas été expulsées édifièrent des hôpitaux privés, avec des chapelles imbriquées dans les bâtiments hospitaliers (chapelle des Sœurs Sainte-Marie-de-la-Famille, rue Blomet). Par ailleurs, des dispositions furent prises pour briser le système de la «mainmorte » des communautés féminines ${ }^{43}$, comme la nouvelle "taxe d'accroissement » imposée en 1884 (droit de succession après chaque décès), mesure qui suscita une ferme résistance de la part des sœurs devenues très riches (Dames du Sacré-Cœur, Dames de l'Assomption, Sœurs de Saint-Joseph-de-Cluny).

L'opinion publique souhaitait freiner l'expansion des congrégations ; une première loi, en 1901, les somma de déclarer leurs biens et de se soumettre à l'autorité de l'évêque. Par la suite, la politique anticléricale très rigide d'Émile Combes, président du Conseil de 1902 à 1905 et nouveau ministre de l'Intérieur, le conduisit à refuser toute demande d'autorisation, jusqu'à ce que la loi du 7 juillet 1904 interdise l'ensemble des congrégations enseignantes. Cette fracture politique entre l'église et la République suscita les protestations de l'archevêque de Paris, accompagnées d'une demande d'explications du nonce apostolique et d'une pétition de soixante-quatorze évêques, jusqu'à la rupture des relations diplomatiques avec le Vatican. La loi du 9 décembre 1905 enfin, instituant la Séparation des Églises et de l'État tout en maintenant la liberté des cultes, signifia l'arrêt des financements et de l'intervention de l'État dans les affaires des Églises et vice-versa ; les biens gérés par des établissements d'État furent transférés à des associations cultuelles, tout en restant la propriété de l'État, des départements ou des communes $^{44}$. L'Église opposa à cette loi une forte résistance et obtint l'entretien par les communes de la totalité des édifices du culte construits avant 1905. Les décrets de 1901 et 
1904 sur les congrégations seront suspendus le 2 août 1914, lors de la déclaration de la Première Guerre mondiale.

D'après le Guide pratique du Paris religieux, Paris comptait en 1994 près de 200 communautés religieuses, dont 150 féminines et 50 masculines (fr.wikipedia.org/wiki/ Liste_des_congrégations_catholiques).

\section{Paris, foyer de renouveau : architecture et vitrail néogothiques}

Figure 6

Entre 1830 et 1930, la population parisienne passe de 750000 à 5 millions d'habitants; pour des raisons financières, la construction de nouvelles églises prend un retard considérable. Afin d'apporter une solution à l'engorgement des paroisses, les instances administratives du Second Empire et de la III République procèdent à la construction de 32 églises à Paris entre 1860 et 1905. Dans notre étude, une chapelle et une église ont été construites sous la Restauration, sept chapelles et trois églises sous le Second Empire (fig. $\mathbf{n}^{\circ} 7$ ), neuf chapelles sous la III' République (jusqu'à la Séparation de 1905) (fig. $\mathbf{n}^{\circ} \mathbf{8}$ ). Paradoxalement, la Séparation de 1905 permit la construction de nouveaux lieux de culte jusqu'à la Première Guerre mondiale : entre 1905 et 1912 furent crées à Paris neuf paroisses nouvelles et vingt-cinq «chapelles de secours » par l'€uvre des chapelles de secours (dans notre corpus, il s'agit de la chapelle Sainte-Jeanne-d'Arc et de SaintHippolyte). Le goût néogothique perdura jusqu'après la Première Guerre mondiale: preuves en sont l'agrandissement de Saint-Hippolyte en 1922-1924, l'érection de la chapelle des Orphelins d'Auteuil en 1924-1925 et de la chapelle de la Mère-de-Dieu en 1930, pour ne parler que des lieux de culte catholiques. Il faudra attendre les années 1950 pour que l'architecture religieuse se dégage des références néogothiques et fasse œuvre de plus grande liberté.

\section{Figure 7}

[Image non convertie]

Saint-Jean-Baptiste-de-Belleville, vue intérieure

(c) Martin Argyroglo Callias Bey, 2008

Figure 8

\section{[Image non convertie]}

Chapelle Sainte-Marie-de-la-Famille, vue intérieure

Phot. Jean-Bernard Vialles, 2008. @ Région île-de-France-Inventaire général / ADAGP

Pendant la première moitié du XIX ${ }^{\mathrm{e}}$ siècle, les églises appartiennent aux communes chargées des travaux de réparation ou de construction, alors que les travaux d'entretien et de décor dépendent des fabriques ; cependant, l'administration des Cultes est amenée à 
donner des conseils sur les coûts et la valeur esthétique des projets. En 1830, la création du Service des monuments historiques avec Ludovic Vitet (1802-1873) puis Prosper Mérimée (1803-1870) comme premiers inspecteurs généraux, est bientôt suivie de celle d'une Commission des monuments historiques $(1837)^{45}$. Seule la construction des chapelles de secours et des succursales relève de l'évêché, contrairement aux églises paroissiales, dont les projets doivent recevoir l'accord du ministère de l'Intérieur ${ }^{46}$. Avant 1848, seuls les architectes des départements ou d'arrondissement sont consultés. Entre 1848 et 1853, la réforme du Service des édifices diocésains permet au ministère des Cultes de faire triompher ses vues grâce aux architectes diocésains qui en dépendent ${ }^{47}$. Une Commission des arts et édifices religieux, comprenant une section "vitraux et ornements ", est créée en 1848 afin de contrôler les plans et devis pour les travaux d'architecture et de décoration exécutés par la Ville de Paris, avant approbation du ministère des Cultes. Dans ses recommandations, elle préconise très schématiquement le style néogothique pour les édifices construits dans le nord de la France et le néo-roman pour le sud. Cette Commission laissa place en 1853 à un Comité des inspecteurs généraux des édifices diocésains.

\section{Le «temps des archéologues »}

29 Marquée principalement par Adolphe-Napoléon Didron dit l'Aîné (1806-1867), JeanBaptiste Lassus (1807-1857) et Eugène Viollet-le-Duc (1814-1879), cette période s'ouvre avec les grands chantiers de restauration de la basilique de Saint-Denis, de la cathédrale Notre-Dame et de la Sainte-Chapelle de Paris. Alexandre Lenoir (1761-1839) avait fondé en 1795 le musée des Monuments français pour sauver des objets religieux du Moyen Âge et de la Renaissance, volés pendant la Révolution; cette première grande collection publique, qui ferma en 1816, tint un rôle de tout premier plan dans l'engouement des Français pour la période du Moyen Âge et dans l'incitation des collectionneurs à la générosité. Le même Alexandre Lenoir publia en 1824, à la demande du comte de Chabrol, préfet de la Seine, un Rapport sur la peinture sur verre, où il affirmait son goût pour le vitrail médiéval. Quant à Adolphe-Napoléon Didron, il va réellement créer la science archéologique, tournée principalement vers le Moyen Âge, dont il admirait les méthodes de construction, l'enseignement et l'iconographie; il adopta une position minimaliste en matière de restauration, se limitant à l'entretien, à la consolidation et à la réparation. Par ses publications, A.-N. Didron fut le porte-bannière du néogothique ${ }^{48}$ et permit l'éclosion de toutes sortes de manifestations de ce retour au Moyen Âge.

Dans ce terreau archéologique, les sociétés savantes, dissoutes en 1793, se reconstituèrent sous le Premier Empire, telle la Société pour la conservation des monuments en 1834, devenue plus tard la Société française d'archéologie. Des publications telles que le Génie du christianisme par Chateaubriand en 1802, Notre-Dame de Paris par Victor Hugo en 1831, les Monuments de France par Alexandre de Laborde entre 1816 et 1826, les Voyages pittoresques et romantiques dans l'ancienne France par Taylor et Nodier entre 1820 et 1878, suscitèrent un engouement réel pour le Moyen Âge et ses ruines, en même temps qu'un renouveau du mysticisme religieux, proches d'un certain « romantisme gothique »; les styles « troubadour » ou « à la cathédrale » connurent alors un regain certain, encouragé par le roi Louis-Philippe. Le clergé se montra favorable lui aussi au retour à l'art du Moyen Âge, y voyant un moyen de revenir à la foi médiévale. Des cours d'archéologie médiévale furent organisés pour les futurs prêtres: ainsi l'abbé 
Godard dans un cours d'archéologie sacrée destiné aux prêtres, remarquait-il que « les verrières de couleur sont si favorables à la piété que les fidèles, en entrant dans certaines églises pour prier, se dirigent instinctivement vers les chapelles qui en sont décorées ${ }^{49}$, et l'abbé Migne publia-t-il une encyclopédie théologique impressionnante traitant de nombreux sujets de la « science religieuse ».

Viollet-le-Duc domine toute la production française archéologique entre 1845 et 1870 : il repense tout le programme vitré de Notre-Dame, puis il est nommé en 1846 dans la commission chargée de préparer la restauration des vitraux de la Sainte-Chapelle. Particulièrement attentif au Moyen Âge et surtout à la fin du XIV et au XV $\mathrm{XV}^{\mathrm{e}}$ siècle ${ }^{50}$, il impose ses vues dans tous les domaines, et va au-delà de la tâche purement archéologique en réinventant des décors ; après les restaurations successives de la Madeleine de Vézelay en 1840, de Carcassonne, de Saint-Sernin de Toulouse, de Notre-Dame de Paris (concours de 1842), de Saint-Denis avec François Debret (1813-1879) et de la Sainte-Chapelle (1836-1855), la restauration du château de Pierrefonds lui valut un grand succès auprès du public.

\section{Le « temps des architectes»}

Figure 9

[Image non convertie]

Sainte-Clotilde, vue extérieure

Phot. Martine Callias Bey, 2008. (c) Centre André Chastel

La démarche archéologique était soumise à la prédominance des architectes diocésains ; une période plurielle s'annonçait, éclectique autant en architecture qu'en vitrail. Des styles architecturaux divers, du néo-roman jusqu'au romano-byzantin, en passant par le «troubadour ", du gothique archéologique néoclassique jusqu'à l'architecture métallique et le béton, coexistèrent dans le paysage parisien. Viollet-le-Duc lui-même abandonna le gothique en 1866-1868 dans son projet, non réalisé, pour Saint-Pierre-de-Chaillot, où il optait pour le roman. Le triomphe plus tardif du néo-roman, du romano-byzantin et du byzantin trouva sa justification dans une plus grande proximité avec l'art antique et avec les origines du monde chrétien; des raisons économiques entrèrent aussi en jeu, le néoroman s'avérant moins coûteux que le néogothique très chargé de sculptures à l'image de Sainte-Clotilde (fig. $\mathbf{n}^{\circ} \mathbf{9}$ ). La proportion de constructions de style néogothique pendant la période 1816-1914 est de loin inférieure à la quantité d'édifices érigés selon des modèles romans, classiques et byzantins, éclectiques souvent ( 26 pour 116 édifices de culte catholique répertoriés à ce jour).

En ce qui concerne notre corpus d'édifices néogothiques parisiens, une pléiade d'architectes en sont les auteurs ${ }^{51}$. Le financement de la construction des nouveaux lieux de culte trouva parfois son origine dans le dynamisme exceptionnel de certains curés qui prônèrent auprès des architectes des solutions économiques et inventives, comme à Saint-Eugène où l'abbé Coquand imaginait dès 1854-1855 avec l'architecte L.A. Boileau (1812-1896) l'association fer/style gothique (fig. $\mathbf{n}^{\circ} \mathbf{1 0}$ ). 
Figure 10

[Image non convertie]

Saint-Eugène, vue intérieure. Phot. Christophe Fouin

(c) Ville de Paris - COARC

La Séparation des Églises et de l'État en 1905 vit la fin du monopole des architectes de l'État ou de la Ville de Paris (Astruc [1862-1935] ou Vaudremer [1829-1914]... peu sollicités en réalité) et la naissance de l'Union syndicale des architectes français; ses membres, Anatole de Baudot (1834-1915) le fondateur en 1890, élève de Viollet-le-Duc, et des architectes des Monuments historiques, se tournaient encore très volontiers vers le rationalisme du XIX ${ }^{e}$ siècle, avec une nette prédilection pour le style gothique ou le romano-byzantin ${ }^{52}$.

\section{Les vitraux néogothiques de Paris}

Paris eut une importance stratégique dans la renaissance du vitrail car c'est là que se rencontrèrent peu avant 1830 archéologues (Didron l'Aîné [1805-1868], François de Guilhermy [1809-1878]), chimistes (Brongniart [1770-1847], Bontemps [1801-1882]), peintres et personnalités des arts, instances administratives et premiers ateliers. Le tout premier atelier parisien, dirigé par Abel de Pujol ${ }^{53}$, fut ouvert à la Foire Saint-Laurent en 1825 par le comte de Chabrol pour les artistes anglais Warren-White et Jones. Le vitrail néogothique ne s'imposa qu'un peu plus tard, en réaction aux essais de peinture aux émaux que certains artistes pratiquaient à la Manufacture de Sèvres. La première verrière néogothique de Paris, une Passion en 14 scènes posée en 1839 à Saint-Germain-l'Auxerrois (fig. $\mathbf{n}^{\circ}$ 11), date de $1839^{54}$.

\section{Figure 11}

38 [Image non convertie]

Passion, verrière d'axe de la chapelle de la Vierge de Saint-Germain-l'Auxerrois, par Reboulleau sur un carton de Louis-Auguste Steinheil, sur les conseils d'Adolphe-Napoléon Didron et sous la direction de Jean-Baptiste Lassus, 1839. Bouchon, Chantal. « Une approche du vitrail (1800-1850) », LE VITRAIL AU XIXE ET LeS ATELIERS MANCEAUX, Le Mans, 1998, p. 27

Repro. Martine Callias Bey, 2008. (c) Centre André Chastel

Un certain romantisme s'interrogeait sur l'existence des « secrets perdus » de la peinture sur verre... ce lieu commun tourna court avec la réédition par le comte charles de l'Escalopier en 1843 du Traité sur les Divers Arts, écrit au XII ${ }^{\mathrm{e}}$ siècle par le moine Théophile. Celui-ci remit à l'honneur les bases de la technique médiévale de la peinture sur verre: les trois valeurs de grisaille, les verres de petites dimensions, des couleurs vigoureuses et un réseau de plomb renforçant le dessin. Les peintres verriers suivaient déjà les recettes du traité de Pierre Le Vieil (1774) et les enseignements publiés par les historiens de la peinture sur verre les plus fiables que furent alors Langlois $(1823,1832)$, Thevenot (1837) et Ferdinand de Lasteyrie (1857). Il existait aussi des manuels pratiques concernant le métier de "vitrier» (Doublette-Desbois en 1828 et Maviez en 1836). Le chimiste Reboulleau, qui avait procédé à la cuisson et à la peinture des verres du vitrail archéologique de Saint-Germain l'Auxerrois en 1839, se démarqua des «façons anciennes » dans un traité sur la renaissance du vitrail publié en 1843 ; Le Vieil fut alors 
jugé dépassé5 ${ }^{55}$. L'architecte Jean-Baptiste Lassus et Adolphe Didron l'Aîné, en tant que théoriciens $\mathrm{du}$ mouvement néogothique ${ }^{56}$, appréciaient particulièrement le peintre verrier Antoine Lusson, lui accordant un rôle de premier ordre dans la renaissance du vitrail archéologique ${ }^{57}$. Celui-ci participa en effet à la restauration de la Sainte-Chapelle de 1849 à 1855, ce qui contribua à le faire connaître et apprécier. Dans les années suivantes, il participa à la création des vitraux de Saint-Eugène et de Sainte-Clotilde.

Figure 12

Baptême de Clovis, nef sud de la chapelle de Bourbon-Condé, par Charles-Émile Hirsch,1884 Phot. Jean-Bernard Vialles, 2007. (c) Région Île-de-France-Inventaire général / ADAGP 
Peut-on parler d'un vitrail «romantique» à propos du vitrail néogothique? Certainement, dans le sens de la première révolution romantique, férue de thèmes monarchistes et chevaleresques, adepte de la ferveur catholique traditionnelle. Le courant né de la chevalerie et du christianisme, passionné pour le Moyen Âge, refusait les modèles classiques et recherchait une esthétique moderne à travers le christianisme et son histoire: ainsi l'iconographie du vitrail néogothique laissa-t-elle une place importante aux saints de l'histoire de France et aux épisodes légendaires, fondateurs d'une certaine mythologie chrétienne (fig. $\mathbf{n}^{\circ} \mathbf{1 4}$ ). Les deux verrières à médaillons consacrées à la vie de saint Louis, posées en 1860 par Laurent-Gsell à Sainte-Clotilde, en sont un exemple typique, et le penchant doloriste de certaines représentations comme les Crucifixions ou autres scènes de la Passion, les scènes de martyre, la Vierge de douleur, etc. participe de cette perspective religieuse et mystique.

Le vitrail néogothique, après le XVIII ${ }^{\mathrm{e}}$ siècle empreint de rationalité, s'apparente bien au « romantisme », ne serait-ce qu'en fonction d'une inclination nouvelle pour la couleur et pour l'obscurité. Alors que «la lumineuse obscurité du chœur reste à cet instant aussi sombre, aussi imposante, aussi favorable au recueillement religieux et à la prière... ${ }^{60}$, et que «l'association pénombre-mystère constitue l'un des aspects majeurs de la quête religieuse du XIX $\mathrm{X}^{\mathrm{e}}$ siècle ${ }^{61}$, la question de la diffusion de la lumière se pose dans les chapelles comme dans les églises. Dans la première moitié du siècle, contrairement aux pratiques du siècle précédent, et dans un souci d'amélioration du confort des fidèles, on en vient à lutter autant contre le froid, contre le bruit que contre l'éclat de la lumière, par la pose de rideaux ou de stores en étoffe devant les verrières et en appliquant un dépoli aux verres ${ }^{62}$. Finalement, le délabrement des rideaux aboutit rapidement à la réhabilitation du vitrail de couleur. Et pourtant, ce dernier fut accusé bientôt d'ôter trop de lumière, notamment le vitrail néogothique archéologique; c'est ce qui explique le succès que rencontrèrent alors des verrières inspirées de la Renaissance qui, elles, laissaient passer beaucoup plus de clarté. «Le vitrail doit, pour rester dans une fenêtre dont le but est d'éclairer, éviter les grands fonds d'ombres et le verre doit être peu couvert de couleur $»^{63}$, et surtout, il fut conseillé de recourir aux vitreries ornementales néogothiques, soit pour servir de complément dans une baie, soit pour occuper des baies entières.

Voir le tableau: LES CONSTRUCTIONS NEO-GOTHIQUES PARISIENNES ET LEURS VERRIERES - EGLISES ET CHAPELLES CATHOLIQUES

\section{Bilans d'un inventaire}

48 La répartition géographique des édifices retenus reflète exactement l'expansion parisienne au cours du $\mathrm{XIX}^{\mathrm{e}}$ siècle: sur ce corpus de 27 constructions néogothiques possédant encore leurs vitraux, huit sont situées dans les arrondissements I à VI, huit dans les arrondissements de VII à XI (correspondant à l'enceinte des Fermiers généraux), onze dans les XII è XXe (correspondant aux villages de banlieue annexés en 1860).

Un seul ensemble de verrières est antérieur à 1850, constitué par l'ensemble de la vitrerie, non signées, de Notre-Dame-du-Bon-Secours, chapelle construite par l'architecte Breton en $1843-44^{64}$ et dont les vitraux furent commandés à la Manufacture de Choisy. Mais c'est la restauration de Notre-Dame de Paris qui suscita le grand élan de création archéologique dans le domaine de la peinture sur verre; dès 1855, Charles Maréchal de 
Metz composait dans la sacristie de la cathédrale nouvellement construite, une série de prélats médiévaux et contemporains, en hommage à Mgr Affre, tué sur les barricades en 1848.

Dans le corpus d'édifices néogothiques étudié, la Manufacture de Sèvres n'est pas du tout représentée et celle de Choisy fournit en vitraux un seul édifice à notre connaissance, Notre-Dame-du-Bon-Secours vers 1844 ; le caractère unique de ce chantier parait d'autant plus incompréhensible que Bontemps, son directeur, fut médaillé en 1834 et 1839 pour des verrières néogothiques. En revanche, ces deux manufactures formèrent un certain nombre de peintres verriers, Oudinot, Lusson, Gsell, appelés à réaliser la plupart des verrières de Sainte-Clotilde, posées dans les années 1853-1860, ou celles de Saint-Eugène entre 1854 et 1858. On retrouve une juste assimilation des modèles de vitrerie ornementale du Moyen Age à la chapelle des Jeunes de Saint-Vincent-de-Paul, dont les verrières non signées en ont un parfait exemple, destiné à une simple chapelle de patronage, construite en 1856. La grande chapelle des Jésuites, dédiée à Saint-Ignace, présente de hautes lancettes figuratives ou ornementales posées vers 1857-1858 par l'atelier Gsell-Laurent ${ }^{65}$, très conformistes dans leur inspiration néo-médiévale ; au cours des années 1860-1870, le vitrail néogothique est encore très bien représenté par les ensembles de la chapelle des Sœurs de Saint-Joseph-de-Cluny, vitrée en 1860 par Charles Lévêque, des églises Saint-Bernard-de-la-Chapelle (1861-1870) (fig. $\mathbf{n}^{\circ}{ }^{15}$ ) et Saint-JeanBaptiste-de-Belleville (vers 1863) (fig. $\mathbf{n}^{\circ}$ 16), du beffroi de Saint-Germain-l'Auxerrois (1862), de la chapelle Notre-Dame-des-Anges (1866) et de Saint-Joseph-Artisan (1867, 1875). La production de ces verrières nettement inspirées du XIII ${ }^{\mathrm{e}}$ laissa place par la suite et jusqu'à la Première Guerre mondiale à des créations beaucoup plus éclectiques, mêlant les références à des époques différentes; ainsi en est-il des verrières de Sainte-Rosalie (1872), des chapelles de l'orphelinat Saint-Charles (1874-1876), de Bourbon-Condé (1884), du Bon-Secours-de-Troyes (1885), de Sainte-Marie-de-la-Famille (1899-1900), de SaintAndré de l'Europe (vers 1897 ?), de Notre-Dame du Liban (1899), de Sainte-Jeanne d'Arc (1913) et de Saint-Hippolyte (1913, 1922). La chapelle Sainte-Thérèse-de-l'Enfant-Jésus $(1927)^{66}$ et Notre-Dame-du-Bon-Conseil $(1936,1945)$ appartiennent à l'entre-deux-guerres.

Figure 15

[Image non convertie]

Saint Mathias, collatéral de Saint-Bernard-de-La-Chapelle, par Eugène Oudinot, vers 1861 (C) Martin Argyroglo Callias Bey, 2008

Figure 16

[Image non convertie]

Portement de croix, Calvaire, Déploration sur le corps du Christ, Résurrection, Ascension, Pentecôte verrières d'axe de Saint-Jean-Baptiste-de-Belleville, par Auguste de Martel, 1863, d'après des cartons de Louis-Auguste Steinheil

(C) Martin Argyroglo Callias Bey, 2008

\section{Commandes et donations}

53 Les édifices cités appartiennent tantôt à des communautés religieuses, tantôt à la Ville de Paris, s'ils ont été construits avant 1905: c'est le cas de Sainte-Clotilde, Saint-Eugène, Saint-Bernard-de-la-Chapelle et Saint-Jean-Baptiste-de-Belleville, ou encore au diocèse de 
Paris quand il s'agit d'anciennes chapelles devenues paroisses et rachetées par le diocèse, comme Saint-André de l'Europe, Saint-Ignace, Saint-Joseph-Artisan, Sainte-Rosalie, ou d'une église construite après 1905 comme Saint-Hippolyte. Ces différentes tutelles interviennent dans la commande des vitraux. En ce qui concerne les édifices appartenant à des ordres religieux, ce sont les communautés elles-mêmes qui s'en chargent, après avis de l'architecte. Il n'est pas rare qu'il se passe dans ce cas quelques années entre l'achèvement de la construction et la pose de sa vitrerie, du fait de financements aléatoires. Pour un édifice appartenant à la Ville ou à l'État, le curé ou l'évêque s'adresse au ministre de l'Intérieur pour demander la pose d'un décor vitré (en précisant parfois l'artiste ou le sujet souhaité) : "lorsqu'il s'agira de travaux de verrières, l'architecte présentera à l'agrément du ministre l'artiste auquel il proposera de les confier et soumettra ensuite les cartons du projet à l'approbation du gouvernement ${ }^{67}$ et l'État passe alors commande auprès des artistes. Il est à noter que les chantiers reçurent davantage de subventions de la part du ministère de l'Instruction publique et des Cultes sous le Second Empire que sous la III ${ }^{e}$ République, de plus en plus réticente vis à vis de l'Église.

\section{Figure 17}

\section{[Image non convertie]}

Planche commerciale de l'atelier de Charles Champigneulle, fin du XIX'e siècle. Blondel, Nicole. LE VitraIL. VOCABULAIRE TYPologique ET TeChNique. Paris : Imprimerie nationale, 1993, p. 219 fig. 407 Repro. Martine Callias Bey, 2008. C Centre André Chastel

Ce n'est donc pas le donateur qui choisit le peintre verrier, mais l'architecte, le conseil de fabrique ou le clergé. Une rencontre privilégiée entre un architecte et un peintre verrier sur un chantier peut être déterminante pour la commande d'autres chantiers; ainsi Viollet-le-Duc a-t-il souvent travaillé avec les peintres verriers Gérente, Lusson, Oudinot ou Maréchal ${ }^{68}$. Sinon, l'architecte sélectionne l'artiste en fonction de ses travaux antérieurs et des prix compétitifs qu'il publie dans des catalogues ou dans des encarts publicitaires parus dans des journaux ou revues ecclésiastiques, offrant un large choix de motifs, de modèles et de styles. (fig. $\mathbf{n}^{\circ}$ 17) Il existe à partir de 1850 des annuaires qui recensent les ouvriers et entreprises du bâtiment ainsi que les artistes, notamment les peintres verriers ${ }^{69}$. Les Salons et Expositions régionales puis industrielles nationales ou internationales, ainsi que les Expositions universelles sont aussi l'occasion de faire connaître et apprécier de nouveaux talents auprès des commanditaires éventuels, tels Maréchal qui fut consacré à Londres en 1851 ainsi qu'Alfred Gérente et Antoine Lusson ${ }^{70}$.

Figure 18

\section{[Image non convertie]}

Sœur Rosalie Rendu présentée par sainte Rosalie à la Vierge à l'Enfant et à saint Vincent de Paul, verrière d'axe de Sainte-Rosalie, par Édouard-Amédée Didron, 1872

Phot. Chloé Bazaud, 2009. @ Région Île-de-France-Inventaire général / ADAGP

57 Les prix étaient élevés, de $50 \mathrm{~F}$ le mètre superficiel à $600 \mathrm{~F}^{71}$ selon trois types de vitraux proposés: légendaires à médaillons (assez chers car ils supposent des recherches iconographiques poussées) ou à personnages sous arcades (moins chers car ils sont fabriqués d'après des remplois de cartons existants) ou encore verrières-tableaux (les plus onéreuses) ; les grisailles, fonds de mosaïques, damas et encadrements d'architecture 
venaient en compléments ${ }^{72} .25500 \mathrm{~F}$ furent alloués à Émile Thibaud pour l'exécution des trois roses de Sainte-Clotilde, la totalité de la vitrerie de cette église ayant coûté $223510 \mathrm{~F}$ dont $46400 \mathrm{~F}$ pour les cartons et $133460 \mathrm{~F}$ pour la peinture sur verre ${ }^{73}$. Certains artistes savaient adapter leur prix à une clientèle moins aisée, comme Édouard Didron (à SainteRosalie en 1872) ou Charles Maréchal, qui pratiquait déjà une production "en série », au moyen notamment de verres imprimés. En ce qui concerne les décors des chapelles, les financements provenaient souvent des dons privés, et ceux des églises paroissiales émanaient des familles des fabriciens, du clergé et des membres des confréries ${ }^{74}$. Les souscriptions prenaient souvent du retard, et de ce fait les vitraux étaient posés plus tard, après l'achèvement de la construction: ce fut le cas à Notre-Dame du Liban, ancienne chapelle de l'École Sainte-Geneviève des Jésuites construite en 1893 et dont les vitraux n'ont été posés qu'en 1899, à Sainte-Rosalie, l'ancienne chapelle des Lazaristes terminée en 1869 et vitrée en 1872 (fig. $\mathbf{n}^{\circ}$ 18), ou encore à la chapelle des Sœurs de Saint-Josephde-Cluny, qui dût attendre quatre ans entre son achèvement en 1856 et la pose de ses vitraux en 1860, etc.

Figure 19

\section{[Image non convertie]}

Apparition de la Vierge à Bernadette Soubirous, la Vierge Nouvelle Ėve, l'Église universelle, verrières d'axe de Saint-André de l'Europe, par Georges-Claudius Lavergne, vers 1897 (?) ; don de la famille Lebaudy

(c) Martin Argyroglo Callias Bey, 2008

Les donateurs des verrières recensées dans les édifices néogothiques parisiens appartiennent le plus souvent à la sphère privée ; l'on peut citer pourtant trois exemples de donations officielles, l'une de la part de l'empereur Napoléon III à la chapelle des Jésuites vers 1858 (Saint-Ignace), l'autre de l'empereur François-Joseph à Saint-JosephArtisan en 1867, alors que cette église était encore occupée par la mission allemande de Paris, une autre par le Prince Napoléon, fils du roi Jérôme, pour la chapelle de son Palais Royal (actuellement le Conseil d'État). Beaucoup de donations se font sous le signe de l'anonymat, mais on trouve aussi mention de simples paroissiens, comme à la chapelle des Jeunes de Saint-Vincent-de-Paul, dont les verrières ornementales ont été données en 1856 par Félix Le Gentil, fondateur du patronage, ou à la chapelle de l'orphelinat SaintCharles, dans laquelle les noms des donateurs figurent au bas des verrières ornementales ${ }^{75}$, ou encore à Saint-André de l'Europe, dont la famille Lehardy a donné la baie 100 et peut-être l'ensemble des trois verrières d'axe (fig. $\mathbf{n}^{\circ}$ 19). Il arrive que les ouvriers du chantier offrent eux-mêmes une verrière : c'est le cas à Sainte-Rosalie, où l'architecte, Henri Marchand a également participé à la donation, ou à la chapelle Sainte-Jeanne d'Arc dont la verrière de Saint-François d'Assise a été offerte par Paul Courcoux en 1912. Les donateurs issus de l'aristocratie se font connaitre, non seulement par des inscriptions, mais aussi par des armes et devises, figurant sur les soubassements ou aux tympans, comme le comte de Chambrun à la chapelle de Bourbon-Condé, ou les familles de SaintRemy, de Pontoipontcarre, Dulac de Fugères et autres à la chapelle Sainte-Marie-de-laFamille en 1899.

60 Les inscriptions de donation, toujours situées au bas des verrières dans le filet inférieur, comportent généralement le nom du donateur en lettres majuscules, précédé de «don de » ou « offert par ». Certains contemporains ont été représentés comme des donateurs présentant la maquette de leur église, à la façon médiévale, malgré les consignes exprimées en 1899 par Mgr Barbier de Montault demandant d'exclure des représentations 
hagiographiques, les vivants et les morts privés, afin que disparaisse le «scandale » des donateurs occupant tout le champ d'une baie selon une tendance jugée trop vaniteuse ; selon lui, trois conditions s'imposaient à la représentation d'un donateur, à savoir qu'il soit à genoux et priant, de petites proportions et assisté par son patron devant Dieu ou la Vierge $^{76}$.

\section{Les créateurs du vitrail néogothique parisien}

6123 ateliers de peinture sur verre ont été sollicités pour réaliser les verrières des édifices étudiés ; cependant, cinq ensembles demeurent anonymes. Les ateliers identifiés sont les suivants $^{77}$ :

- Bourdon Édouard : Sainte-Clotilde en 1854 (vitrail néo-XIII).

- Chabin Henri : Saint-Eugène vers 1875 (vitrail décoratif et vitrail historiciste)

- Champigneulle II Louis-Charles-Marie et Fils (1853-1905), puis Société artistique de peinture sur verre : chapelle Sainte-Marie-de-la-Famille en 1899-1900 (vitrail-tableau).

- Didron Édouard-Amédée (1836-1902) : Sainte-Rosalie en 1872 (vitrail archaïsant).

- Fournier Lux (1868-1930 ?) : Saint-Hippolyte en 1913, 1922 (vitrail néo-XIII').

- Gérente Alfred (1821-1868) : Notre-Dame de Paris en 1860-1865 (vitrail néo-XIII ${ }^{e}$.

- Geyling Carl (1814-1880) : Saint-Joseph-Artisan en 1867 et 1870 (vitrail historiciste).

- Gsell Jean-Gaspard-Jules (1814-1904) : Sainte-Clotilde en 1851-1856, Saint-Eugène en 1858, chapelle Saint-Ignace des Jésuites vers 1858, Saint-Bernard-de-la-Chapelle en 1861 (vitrailtableau et vitrail historiciste).

- Hirsch Charles-Émile (1832-1904) : chapelle de l'Hôtel-de-Bourbon-Condé en 1884, NotreDame-du-Liban en 1899 (vitrail historiciste).

- Lafaye Prosper (1806-1883) : Sainte-Clotilde en 1853 (vitrail néo-XIII').

- Lavergne Georges dit Georges-Claudius : Saint-André-de-l'Europe vers 1897, chapelle NotreDame du Saint-Sacrement vers 1900 (vitrail-tableau).

- Lévêque Charles ( ?-1889) : chapelle des Sœurs de Saint-Joseph-de-Cluny en 1860 (vitrail néo$\left.X I I I^{e}\right)$.

- Lusson Antoine (1840-1876) : Saint-Eugène-Sainte-Cécile en 1855, 1858, Sainte-Clotilde en 1854 (vitrail historiciste).

- Manufacture de Choisy, atelier de peinture sur verre (1829-1851) : chapelle Notre-Damedu-Bon-Secours vers 1844 (vitrail néo-XIII)

- Maréchal Charles-Laurent (1801-1887) : sacristie de Notre-Dame de Paris en 1855, SainteClotilde en 1858-1860 (vitrail historiciste).

- Martel Auguste (de) : Saint-Jean-Baptiste-de-Belleville en 1863 (vitrail néo-XIII).

- Mauméjean Jules-Pierre le Père (1837-1909) et ses fils : chapelle Sainte Thérèse de l'EnfantJésus en 1927, Notre-Dame-du-Bon-Conseil à la fin du XIXe ? et 1936 (vitrail Art décoratif).

- Oudinot Eugène-Stanislas (1827-1889) : Sainte-Clotilde entre 1851 et 1854, Saint-EugèneSainte-Cécile en 1854, Saint-Bernard-de-la-Chapelle en 1861-1870, beffroi de Saint-Germainl'Auxerrois en 1862, et la chapelle du Conseil d'État en 1862 (vitrail historiciste).

- Pé François : chapelle des Sœurs de Notre-Dame-du-Bon-Secours-de-Troyes en 1885.

- Petit-Gérard Pierre (1852-1921) : Saint-Eugène-Sainte-Cécile vers 1875 ( ?) (vitrail décoratif).

- Thevenot Étienne-Hormidès (1797-1862) : Sainte-Clotilde entre 1851 et 1854 (vitrail néo-XIII ${ }^{e}$ ).

- Thibaud Émile (1810-1896) : Sainte-Clotilde entre 1851 et 1854 (vitrail néo-XIII ${ }^{e}$.

- Villiet Joseph (1823-1877) : chapelle Notre-Dame-des-Anges en 1866 (vitrail néo-XIII'). 
Auteurs non identifiés : chapelles des Jeunes de Saint-Vincent-de-Paul vers 1856, de l'orphelinat Saint-Charles en 1874-1876, chapelle de Jésus-Enfant vers 1881, SainteJeanne-d'Arc en 1913.

Figure 20

[Image non convertie]

Présentation de la Vierge au Temple, Annonciation, chœur de la chapelle Sainte-Marie-de-la-Famille, signée par Charles Champigneulle, datée 1899, inscription de donation (Mme de Saint-Remy)

Phot. Jean-Bernard Vialles, 2008. @ Région Île-de-France-Inventaire général / ADAGP

Quand les signatures existent, elles sont soit calligraphiées, soit "enlevées » sur la grisaille, soit écrites en caractères d'imprimerie, accompagnées ou non de dates, avec une prédominance de la signature unique "d'authentification $»^{78}$. La signature n'est pas toujours très lisible, surtout quand elle est apposée sur les fenêtres hautes. Elle peut être soit unique - c'est le cas le plus fréquent -, comme celles d'Édouard Didron à SainteRosalie, d'Émile Hirsch à la chapelle de Bourbon-Condé, ou de Laurent-Gsell à SaintEugène, soit répétée plusieurs fois, voire deux fois sur une même verrière, comme celle de Charles Champigneulle à la chapelle Sainte-Marie-de-la-Famille (fig. $\mathbf{n}^{\circ} \mathbf{2 0}$ ); elle peut aussi être répétée sur chaque verrière d'un ensemble, comme l'ont fait Charles Lévêque à la chapelle des Sœurs de Saint-Joseph-de-Cluny, Antoine Lusson et Prosper Lafaye à Sainte-Clotilde ou Lux Fournier à Saint-Hippolyte.

D'après A.-N. Didron, la manufacture idéale devait se composer d'un archéologue, d'un dessinateur, d'un peintre, d'un chimiste et d'un verrier, ce qui est le cas de la première équipe engagée à Saint-Germain l'Auxerrois ${ }^{79}$. Quand ils ne dessinaient pas eux-mêmes leurs propres cartons comme Thevenot et Claudius Lavergne, Gsell, Oudinot ou Hirsch, les peintres verriers avaient recours à des cartonniers, soit salariés par l'atelier, soit payés au carton. Dans le cas des verrières de Saint-Jean-Baptiste-de-Belleville, le peintre verrier Auguste de Martel fit appel vers 1863 au peintre Louis Steinheil (1814-1885) (fig. $\mathbf{n}^{\circ} \mathbf{2 1}, \mathbf{n}$ - 22) ; celui-ci, ayant acquis de fait une grande notoriété, ne réalisa plus que des cartons de vitraux jusqu'à la fin de sa vie, après avoir quasiment abandonné la peinture; les commandes lui étaient passées directement et il restait propriétaire de ses cartons ${ }^{80}$.

Figure 21

[Image non convertie]

Adam et Ève chassés du Paradis, carton à grandeur d'exécution de Louis-Charles-Auguste Steinheil pour la verrière de Saint-Jean-Baptiste-de-Belleville, réalisée par Auguste de Martel, 1863. Luneau, Jean-François. «Vitrail archéologique, vitrail-tableau. Chronique bibliographique », REVUE DE L'ART, $\mathrm{n}$ 124, 1999-2, fig. 7. p. 74

Repro Martine Callias Bey, 2008. (c) Centre André Chastel

Figure 22

67 [Image non convertie]

Adam et Ève chassés du Paradis, verrière haute de la nef de Saint-Jean-Baptiste-de-Belleville, par Auguste de Martel, d'après un carton de Louis-Charles-Auguste Steinheil, vers 1863

Phot. Martine Callias Bey, 2008. ( C Centre André Chastel 
Figure 23

68

\section{et Paul Jourdy, 1854 \\ Phot. Martine Callias Bey, 2008. (c) Centre André Chastel}

Transfiguration, carton de Johann-Gaspard-Julius Gsell pour Saint-Eugène, conservé au Cabinet des Arts graphiques du Musée Carnavalet

Phot. Martine Callias Bey, 2008. (c) Centre André Chastel. (voir fig. 30)

71 Dans de nombreux cas, les peintres verriers engagés sur les chantiers néogothiques dessinaient eux-mêmes leurs cartons ; sauf à Sainte-Clotilde où, hormis Maréchal qui réalisait projets et verrières, les peintres verriers ont préféré s'adresser à des peintres formés dans les ateliers de Gros (1771-1835) (Hesse [1806-1879] ${ }^{81}$ pour Laurent-Gsell), d'H. Flandrin (1809-1864) (Lamothe [1822-1869] et Chancel pour Lafaye et Oudinot), et d'Ingres (1780-1867) (Amaury-Duval [1808-1885], Jourdy [1805-1856] et Galimard [1813-1880] pour Lusson), ou même à l'architecte Théodore Ballu (1817-1885) pour les parties ornementales. Autres exceptions : à Saint-Eugène, Oudinot a eu recours au cartonnier Gérard-Seguin (1805-1875), à Saint-Jean-Baptiste-de-Belleville, Auguste de Martel s'est adressé à L.C.A. Steinheil, comme nous l'avons déjà vu, tandis que Mauméjean, à la chapelle Sainte-Thérèse-de-l'Enfant-Jésus, a collaboré avec l'architecte Henri Chailleux. Ces peintres ont-ils signé leurs œuvres ? Rarement et dans ce cas, leur nom est suivi, ou non, de INVENIT : à Sainte-Clotilde, on trouve au bas des baies des collatéraux de la nef, au sud, P. JOURDY INVENIT 1854 Paris, MANre Le Mans A. LUSSON E. BOURDON, et au nord, A. GALIMARD INVENIT 1854 A. LUSSON et E. BOURDON Paris et Le Mans (fig. $\mathbf{n}^{\circ} \mathbf{2 4}$ ). La question de l'identité des cartonniers se pose encore pour les 37 verrières-tableaux recensées, réalisées par Hirsch, Lavergne et Champigneulle dans sept édifices de notre corpus.

\section{Des « images » de dévotion}

Louis Grodecki met en avant le rôle joué par le vitrail dans le renouvellement de l'iconographie religieuse au $\mathrm{XIX}^{\mathrm{e}}$ siècle ${ }^{82}$. Les «iconographes pratiquants ", comme l'archéologue Adolphe Didron ${ }^{83}$, mettent au point en 1840 un projet de Recueil de modèles au sein du Comité historique des arts et monuments. Les nombreux ateliers qui s'ouvrent alors trouvent aussi des modèles soit dans les verrières anciennes qu'ils restaurent (ainsi l'ancienne abbatiale Saint-Ouen de Rouen a-t-elle servi de modèle pour Sainte-Clotilde, architecture et vitraux), soit dans les reproductions lithographiées publiées dans les grandes monographies des cathédrales ${ }^{84}$. Certaines verrières néogothiques remarquables 
semblent inspirées de modèles anciens, c'est le cas de la Vierge à l'Enfant sous un baldaquin, représentée par Joseph Villiet en 1866 dans la baie d'axe de la chapelle NotreDame-des-Anges (fig. $\mathbf{n}^{\circ} \mathbf{2 5}$ ), ou du Calvaire de Saint-Jean-Baptiste-de-Belleville, (fig. $\mathbf{n}$ - 26) inspiré de la grande verrière du Calvaire surmonté de l'Ascension de la cathédrale de Poitiers, œuvre du XII siècle. Les fonds des ateliers, qui étaient autant de mines documentaires, contenaient tout un éventail d'encyclopédies, de manuels d'iconographies et de monographies, d'albums de miniatures, de gravures, de peintures, de moulages, de photographies et de relevés de verrières anciennes, de sculptures et de fresques, en plus des fonds de dessins propres à l'atelier ${ }^{85}$ et des fonds de cartons provenant d'autres ateliers ${ }^{86}$. En ce qui concerne les verrières ornementales, les Pères Cahier et Martin en ont publié des modèles dans leur monographie Bourges-Vitraux du XIII ${ }^{\mathrm{e}}$ siècle, Paris, 1841-1844, ainsi que Viollet-le-Duc dans son Dictionnaire raisonné de l'Architecture ${ }^{87}$.

Figure 25

\section{[Image non convertie]}

Vierge à l'Enfant, verrière d'axe du triforium de la chapelle Notre-Dame-des-Anges, par Joseph Villiet, 1866

Phot. Philippe Fortin, 2006. (c) Inventaire général / ADAGP

\section{Figure 26}

\section{[Image non convertie]}

Calvaire, Ascension, verrière d'axe de Saint-Jean-Baptiste-de-Belleville, par Auguste de Martel, 1863, d'après un carton de Louis-Charles-Auguste Steinheil

(c) Martin Argyroglo Callias Bey, 2008

5 Faut-il rappeler que l'iconographie réservée à l'axe d'un édifice se rapporte le plus souvent au Christ ou à la Vierge, au saint patron de l'édifice ou du (ou des) donateur (s) des verrières (à Saint-Joseph-Artisan par exemple), ou au vocable d'une communauté : citons la Sainte Famille représentée à la baie d'axe de la chapelle Sainte-Marie-de-laFamille (fig. $\mathbf{n}^{\circ}$ 27), les saintes Clotilde et Valère figurant au-dessus du maître-autel de la basilique Sainte-Clotilde, sainte Rosalie dans la baie d'axe de Sainte-Rosalie ou l'entrée de Jeanne d'Arc à Orléans à la chapelle du même nom.

Figure 27

6 [Image non convertie]

Bénédiction des enfants, Sainte Famille, Présentation de la Vierge au temple, verrières d'axe de la chapelle Sainte-Marie-de-la-Famille, signées par Charles Champigneulle, 1899

Phot. Jean-Bernard Vialles, 2008. @ Région Île-de-France-Inventaire général / ADAGP

D'autre part, certains thèmes s'accordent avec les vocables des chapelles : le Mariage de la Vierge dans les chapelles de mariages, le Baptême du Christ ou le Baptême de Clovis dans les chapelles des fonts baptismaux, l'Immaculée Conception, Notre-Dame-du-Rosaire ou la Vie de la Vierge dans les chapelles de la Vierge. Barbier de Montault en 1899 prône pour les verrières néo-XIIIe légendaires des fenêtres basses, des scènes exclusivement empruntées à l'Écriture et à la vie des saints : « Tout fait purement historique doit être scrupuleusement écarté : l'église n'est pas une galerie où l'on vient se distraire et apprendre à connaître le passé $\rrbracket^{88}$. Les grandes figures sont réservées, comme au Moyen Âge, aux fenêtres hautes, 
avec traditionnellement les personnages de l'Ancien Testament dans les baies nord, et du Nouveau Testament dans les baies sud. Deux exceptions pourtant confirment cette règle : à Sainte-Clotilde et à Saint-Bernard-de-la-Chapelle, dont les fenêtres basses abritent de grandes figures de saints et d'apôtres. Les légendes que l'on trouve portées sur les verrières sont apposées généralement sur un cartouche servant de socle aux figures ou aux scènes ; elles figurent parfois sur un bandeau situé derrière le buste des personnages, dans le plus pur esprit archéologique, comme dans les baies basses des collatéraux de Saint-Jean-Baptiste-de-Belleville.

\section{Les thèmes christiques ${ }^{89}$}

Les lieux de culte catholiques entretiennent une forte dévotion à Jésus-Christ, surtout après 1850 ; les épisodes de sa Vie sont mêlés aux Mystères de la Vie de la Vierge ou font l'objet de verrières-tableaux, comme à Saint-Eugène dès 1855 (fig. $\mathbf{n}^{\circ}$ 28). Le Christ apparaît comme le modèle parmi les modèles ; Il figure à quatre reprises à Sainte-Clotilde, trônant auprès de la Vierge ou de Moïse ou de manière isolée. Son rôle primordial dans la médiation de la Parole divine est réaffirmé dans les baies hautes du chœur de l'église Saint-Bernard-de-La-Chapelle, où Il est représenté entouré des évangélistes, des docteurs de l'Église, de martyrs et de saints fondateurs d'ordres. (fig. $\mathbf{n}^{\circ}$ 29)

Figure 28

[Image non convertie]

Transfiguration, verrière d'axe de Saint-Eugène, par Johann-Gaspard-Julius Gsell et Émile-Laurent, 1855 Phot. Christophe Fouin. (c) Ville de Paris - COARC. (Voir fig. 25)

Figure 29

\section{[Image non convertie]}

Christ trônant entre les évangélistes, les Docteurs de l'Église et des martyrs, verrières hautes du chœur de Saint-Bernard-de-La-Chapelle, par Eugène Oudinot, 1861

(c) Martin Argyroglo Callias Bey, 2008

81 Le Secours chrétien et le Salut, thèmes typiquement gallicans, s'incarnent dans le Christ Bon Pasteur, Agneau pascal, Pélican symbolique, Sacré-Cœur (fig. $\mathbf{n}^{\circ} \mathbf{3 0}$ ) et dans la Crucifixion, dans la baie d'axe de Saint-Ignace vers 1858, soulignés des devises héraldiques PRO DEO, PRO REX. La Passion du Christ devient un sujet de dévotion à Saint-Eugène avec le Chemin de croix, de l'Arrestation du Christ à sa Déposition de croix (fig. $\mathbf{n}^{\circ} \mathbf{3 1}$ ), et à Sainte-Clotilde avec les Symboles de la Passion représentés par Oudinot dans les portes d'entrée latérales.

Figure 30 
Figure 31

\section{Arrestation du Christ, Saint-Eugène, par Antoine Lusson, 1855 \\ Phot. Christophe Fouin. (c) Ville de Paris - COARC}

\section{Les thèmes mariaux ${ }^{90}$}

Une iconographie abondante traduit cette dévotion qui reconnaît en Marie un modèle de pureté, de foi et d'humilité. Depuis 1830, date de son apparition à Catherine Labouré, son culte s'est intensifié ; sa vie fait l'objet de cycles souvent complets (Notre-Dame du Liban, chapelle Notre-Dame-des-Anges, chapelle Saint-Ignace, chapelle de Bourbon-Condé, Sainte-Clotilde, Saint-Hippolyte, chapelle Sainte-Marie-de-la-Famille), ou d'images isolées qui la représentent soit en Reine du ciel (Assomption et Couronnement de la baie d'axe de Sainte-Clotilde), soit en Vierge à l'Enfant ( 6 verrières du corpus, dont la très belle verrière d'axe de la chapelle Notre-Dame-des-Anges), soit en Mère du Christ et corédemptrice à ce titre, à Sainte-Clotilde (fig. $\mathbf{n}^{\circ} \mathbf{3 2}$ ), soit en Vierge de l'Apocalypse (chapelle Notre-Dame-duBon-Secours), "femme revêtue de soleil avec la lune sous les pieds et sur sa tête une couronne de douze étoiles... ${ }^{91}$; elle étend alors les bras ou joint les mains, les yeux baissés vers la terre. Sa Parenté et l'Arbre de Jessé figurent sur quatre verrières de notre corpus, tandis que des roses de transept ou de façade lui sont consacrées à Saint-JeanBaptiste-de-Belleville, aux chapelles Notre-Dame-du-Bon-Secours et Notre-Dame-desAnges (fig. $\mathbf{n}^{\circ}$ 33). Les scènes de la vie de saint Joseph sont généralement intégrées dans les Vies de Marie et du Christ, notamment son Mariage, le Doute et la Fuite en Égypte; elles ne sont pratiquement pas représentées pour elles-mêmes.

Figure 32

[Image non convertie]

Le Christ assis, bénissant et la Vierge assise, croisillon du transept de Sainte-Clotilde, par Antoine Lusson et Édouard Bourdon, d'après les cartons d'E. Amaury-Duval, 1855

Phot. Jean-Marc Moser. (c) Ville de Paris - COARC

Figure 33

[Image non convertie]

Vierge à l'Enfant et Litanies, rose de la chapelle Notre-Dame-des-Anges, par Joseph Villiet, 1866 Phot. Philippe Fortin, 2006. ( ) Inventaire général / ADAGP

\section{Les saints $^{92}$}

87 La vénération des saints et saintes protecteurs de la Monarchie, des saints patrons du diocèse de Paris et des personnages édifiants de la chrétienté, est une constante tout au long du siècle dans les édifices parisiens. Nous en avons pour preuve les séries réalisées par Hirsch à la chapelle de Bourbon-Condé et à Notre-Dame du Liban, par Villiet à la chapelle Notre-Dame-des-Anges, par Maréchal, Lafaye et Lusson à Sainte-Clotilde, par Levêque à la chapelle des Sœurs de Saint-Joseph-de-Cluny, par A. de Martel à Saint-JeanBaptiste-de-Belleville, etc. 
Figure 34

[Image non convertie]

Sainte Mathilde et sainte Élisabeth, nef de la chapelle Notre-Dame-des-Anges (détail), par Joseph Villiet, 1866

Phot. Philippe Fortin, 2006. (c) Inventaire général / ADAGP

Parmi eux on distingue les apôtres, avec une prédominance des saints Pierre et Paul, les évangélistes, tout le panthéon des saints du Moyen Âge, les saints de l'histoire de France ( Geneviève, Denis, Blanche de Castille, Charlemagne, Louis, Jeanne d'Arc, Mathilde, Clotilde (fig. $\mathbf{n}$ -34), les saints dont la charité fut exemplaire (saint Martin, saint Vincent de Paul, sainte Élisabeth de Hongrie...), les saints liés aux patronages des églises et des chapelles (à SaintEugène, Saint-Joseph-Artisan, Sainte-Rosalie, chapelle Sainte-Jeanne-d'Arc, chapelle des Sœurs de Saint-Joseph-de-Cluny, chapelle Sainte-Thérèse de l'Enfant-Jésus, SainteClotilde), enfin les saints, saintes ou bienheureux fondateurs d'ordres (Vincent de Paul, François de Sales, Thérèse d'Avila, François d'Assise, Bernard de Clairvaux, Ignace de Loyola, Rosalie Rendu, etc.). La figure de Marie-Madeleine, qui représente l'image du Péché et l'espoir de la Rédemption, figure à plusieurs reprises, à la chapelle Notre-Dame-du-BonSecours vers 1844 , à Sainte-Clotilde vers 1855 , à la chapelle Saint-Ignace vers 1858 , à Saint-Jean-Baptiste-de-Belleville vers 1863, à Saint-Bernard-de-La-Chapelle vers 1865.

Figure 35

[Image non convertie]

L'Arche de Noé, verrière haute de la nef de Saint-Jean-Baptiste-de-Belleville, par Auguste de Martel d'après un carton de Louis-Charles-Auguste Steinheil, 1865

(C) Martin Argyroglo Callias Bey, 2008

Figure 36

[Image non convertie]

Eléazar perçant le ventre d'un éléphant (I Mac VI, 43-46), verrière haute de la nef de Saint-Jean-Baptistede-Belleville, par Auguste de Martel, 1863, d'après un carton de Louis-Auguste Steinheil

(c) Martin Argyroglo Callias Bey, 2008

Figure 37

\section{[Image non convertie]}

Ézéchiel et Daniel, croisillon sud du transept de Sainte-Clotilde, par Prosper Lafaye, 1853

Phot. Jean-Marc Moser. (c) Ville de Paris - COARC

À ces trois grands domaines iconographiques de la première moitié du siècle viennent s'ajouter des figures de l'Ancien Testament (verrières typologiques et histoire des Rois à Saint-Jean-Baptiste de Belleville vers 1863 dans les baies hautes de la nef et du transept (fig. $\mathbf{n}^{\circ} \mathbf{3 5}, \mathbf{n}^{\circ} \mathbf{3 6}$ ) et figures féminines de la chapelle Notre-Dame-des-Anges), quelques scènes de la Genèse (à Saint-Jean-Baptiste-de-Belleville, à la chapelle de Bourbon-Condé et à Saint-André-de-l'Europe), et des prophètes (à Sainte-Clotilde en 1853$)^{93}$. (fig. n $^{\circ}$ 37) 


\section{Du nouveau dans l'iconographie} l'influence du liguorisme, l'accent est mis sur son humanité. Les thèmes douloureux de la Passion reçoivent une dévotion toute particulière, par exemple à la chapelle Notre-Damedes-Anges où une baie entière leur est consacrée. Il faut rappeler à ce sujet que la fête de l'Invention de la Sainte-Croix fut instituée le 3 mai 1897, parallèlement à l'Exaltation de la Sainte-Croix déjà fêtée le 14 septembre. À la chapelle Sainte-Marie-de-la-Famille, Champigneulle a choisi de représenter deux scènes emblématiques de cette piété affective ultramontaine, la Bénédiction des enfants et Jésus au milieu des Docteurs (fig. $\mathbf{n}^{\circ}$ 38). Cette dernière scène est également représentée à la chapelle Notre-Dame-des-Anges par Émile Hirsch. Les figures du Bon Pasteur et du Sacré-Cœur, fréquemment représentées dans les 
nombreuses églises françaises, sont pratiquement absentes des édifices néogothiques parisiens, si ce n'est dans les médaillons néo-XIII e de Saint-Ignace et de Saint-Hippolyte.

Figure 39

[Image non convertie]

Apparition du Sacré-Cœur à Marguerite-Marie Alacoque en présence du Père Eudes, collatéral sud de Notre-Dame-du-Liban, par Charles-Émile Hirsch, 1899

Phot. Philippe Fortin, 2005. (c) Inventaire général / ADAGP

En revanche, l'Apparition du Sacré-Cour à Marguerite-Marie Alacoque, épisode fondateur de cette dévotion, qui s'est déroulé en 1675 à Paray-le-Monial99, est déjà représentée à SaintIgnace vers 1858, et plus tard à Notre-Dame du Liban en 1899 (fig. $\mathbf{n}^{\circ}$ 39), à SaintHippolyte en 1922, à la chapelle Sainte-Thérèse de l'Enfant-Jésus en 1927. Le Coeur sacré de Jésus est représenté à plusieurs reprises : à la chapelle de l'Accueil Louise de Marillac et à Sainte-Rosalie où Jésus Enfant, présenté par la Vierge, montre son Cœur à Sœur Rosalie.

101 L'iconographie mariale nouvelle est plus abondante. Le thème de la Vierge nouvelle Ève ${ }^{100}$, associée au nouvel Adam qu'est Jésus, insiste sur son rôle médiateur dans le déroulement du Salut ; on le trouve représenté par É. Hirsch à Saint-André de l'Europe vers 1897 (fig. n - 40) et à Notre-Dame du Liban en 1899. Dans cette dernière église, on peut voir la Vierge à l'Enfant recevoir la vénération des saints patrons des Jésuites, Ignace de Loyola, Charles Borromée et Louis de Gonzague (fig. $\mathbf{n}^{\circ} \mathbf{4 1}$ ).

Figure 40

[Image non convertie]

Adam et Ėve chassés du Paradis, Jessé et l'arbre de la Vierge, Moïse, Isaïe, le roi David, Vierge nouvelle Ėve, verrière du chœur de Saint-André-de-l'Europe, par Georges Claudius Lavergne, vers 1897 (c) Martin Argyroglo Callias Bey, 2008

Figure 41

[Image non convertie]

Vierge à l'Enfant priée par les saints Ignace de Loyola, Charles Borromée et Louis de Gonzague, collatéral sud de Notre-Dame-du-Liban, par Charles-Émile Hirsch, 1899

Phot. Philippe Fortin, 2005. (c) Inventaire général / ADAGP

La dévotion au Cœur-de-Marie remonte à 1770 ; elle donna lieu plus tard à la dévotion au Cœur-Immaculé-de-Marie puis à la constitution d'une archiconfrérie du Sacré-Cœur-deMarie, approuvée en 1838. Enfin, la proclamation du dogme de l'Immaculée Conception en 1854 par le pape Pie IX vint consacrer officiellement ce culte. Parmi d'autres, la chapelle de l'Accueil- Louise-de-Marillac, ancien orphelinat Saint-Louis, montre les Sacrés-Coeurs de la Vierge et de Jésus (1891).

105 L'iconographie de l'Immaculée Conception, sainte et conçue sans péché, montre la Vierge couronnée d'étoiles et descendant sur terre, debout sur un croissant de lune (d'après un tableau de Murillo) ; elle est ainsi représentée à la chapelle des Sœurs de Saint-Joseph-deCluny en 1860. À Saint-Jean-Baptiste-de-Belleville vers 1863, dans un médaillon du triplet de la chapelle d'axe, la Vierge apparaît auréolée d'une lumière divine dont les rayons tombent de ses mains, conformément à la Vierge de la Médaille miraculeuse, frappée deux ans après son apparition à Catherine Labouré en 1830 (fig. $\mathbf{n}^{\circ}$ 42). Lux Fournier l'a 
également représentée à l'église Saint-Hippolyte en 1926. Les Apparitions de la Vierge ${ }^{101}$ ne sont représentées qu'en 1897, à Saint-André de l'Europe (Apparition à Bernadette de Lourdes ) (fig. $\mathbf{n}^{\circ}$ 43), et en 1936 à Notre-Dame du Bon-Conseil (Apparitions de Notre-Dame-du-BonConseil, de Notre-Dame-de-Lourdes, de Notre-Dame-de-La-Salette, la Vierge de la Chapelle miraculeuse). Ce développement de l'iconographie des Apparitions correspond au grand mouvement de pèlerinages qui se multiplièrent en France à partir de 1872-1873, vers Lourdes et Paray-le-Monial.

Figure 42 IX institue l'Association de son Culte perpétuel, puis le proclame patron de l'Église universelle le 8 décembre $1870^{103}$; plus tard, en 1892, il sera proposé comme patron des ouvriers par le pape Léon XIII. Le plus souvent, il apparaît tenant l'Enfant Jésus, soit isolément, portant le lys, symbole de l'incarnation et de la virginité de la Vierge ou le bâton fleuri évoquant son mariage, ou encore les outils de son métier. Sept verrières de notre corpus lui sont consacrées, notamment à Notre-Dame du Liban, où il côtoie sainte Anne et la Vierge enfant (fig. $\mathbf{n}^{\circ} \mathbf{4 4 )}$ ). À la chapelle des Sœurs de Saint-Joseph-de-Cluny en 1860 , il figure en qualité de patron de la congrégation; à la chapelle Notre-Dame-desAnges en 1864-1866, il est tourné vers la Vierge à l'Enfant ; à Saint-Joseph-Artisan en 1865-1866, il figure en tant que patron du donateur, l'empereur d'Autriche FrançoisJoseph. La scène de sa Bonne Mort, thème qui se développe au $\mathrm{XIX}^{\mathrm{e}}$ siècle sous l'influence des peintres néo-Nazaréens, rappelle son rôle de patron des agonisants et de consolateur des âmes du Purgatoire : c'est ainsi qu'il apparaît à Sainte-Clotilde en 1846-1857, à Saint- 
Ignace vers 1858, à Notre-Dame du Liban en 1899 et à la chapelle Sainte-Jeanne-d'Arc en 1913.

111 La Sainte-Famille, image de la Trinité sur terre, devient un modèle pour les familles chrétiennes et un objet de dévotion; une Association de la Sainte-Famille naquit en mars 1892. Le plus bel exemple de cette nouvelle « icône » est la représentation qui figure dans la baie d'axe de la chapelle Sainte-Marie-de-la-Famille, composée par Champigneulle en 1899-1900.

Figure 45

[Image non convertie]

Aram, Rachel, Abigaël, Judith, nef de la chapelle Notre-Dame-des-Anges, par Joseph Villiet, 1866 Phot. Philippe Fortin, 2006. (c) Inventaire général / ADAGP

113 Le poids de la hiérarchie romaine se fait sentir dans la multiplication de thèmes chers à l'enseignement de l'Église et tout d'abord au travers de ses représentants directs : les figures emblématiques de saint Pierre et des apôtres, des papes et des évêques, des évangélistes, des Docteurs de l'Église, des fondateurs d'ordres, etc. se retrouvent, en plus ou moins grand nombre, dans presque tous les édifices. Georges-Claudius Lavergne a consacré une verrière à L'Église, ses papes et son clergé à Saint-André-de-l'Europe vers 1897, où l'on peut voir deux papes, le cardinal Hippolyte Guibert offrant la maquette de la future basilique du Sacré-Cœur ${ }^{104}$, un saint empereur, saint Pierre, un roi, deux moines, etc. De nombreuses figures de femmes sont aussi proposées à la dévotion, illustrant ce mouvement de féminisation de la religion parvenu de Rome vers 1850 : Rosalie, Constance, Lucie, Mathilde, Marguerite, Jeanne, Juliette, Suzanne, Catherine, Foi, Cécile, etc., et notamment des saintes pratiquant ostensiblement la charité comme Geneviève, Clotilde, Jeanne de Chantal, Élisabeth de Hongrie, Catherine d'Alexandrie, Adélaïde, ou encore les femmes de l'Ancien Testament (chapelle Notre-Dame-des-Anges en 1866) (fig. $\mathbf{n}^{\circ}$ 45). Le thème de la Vocation de saint Pierre et des apôtres évoque la fondation de l'Église, tandis que, sous l'influence d'Alphonse de Liguori, l'exhortation à l'Eucharistie, comme à tous les sacrements, se développe comme l'un des thèmes privilégiés de la spiritualité ultramontaine: à la chapelle Sainte-Marie-de-la-Famille, au-dessus de la Cène, est représenté un ciboire surmonté d'une croix dans une mandorle entourée de deux anges portant l'inscription ECCE CORPUS MEUM ; à Saint-Eugène, c'est la Vierge qui présente l'hostie et le ciboire entre deux anges adorateurs tandis que Maréchal réalise un ange tenant un ciboire dans un tympan de Sainte-Clotilde. La Cène est représentée plusieurs fois, notamment à la chapelle Notre-Dame-des-Anges et à Saint-Jean-Baptiste-de-Belleville.

La dévotion à sainte Jeanne d'Arc ne fait que croître jusqu'à sa béatification par Pie X le 18 avril 1909 : déjà présente à Notre-Dame du Liban en 1899, Jeanne se voit dédier la chapelle de l'avenue Reille en 1913, et un cycle complet de verrières où sont représentés saint Michel, saintes Catherine et Marguerite, les voix qui l'appelèrent à sauver la France, ainsi que son Entrée à Orléans et les blasons des villes qu'elle dut traverser. (fig. $\mathbf{n}^{\circ} \mathbf{4 6}, \mathbf{n}^{\circ} \mathbf{4 7}$ ).

Figure 46

[Image non convertie]

Entrée de Jeanne d'Arc dans Orléans, verrière d'axe de la chapelle Sainte-Jeanne d'Arc, vers 1913

Phot. Jean-Bernard Vialles, 2008. @ Région Île-de-France-Inventaire général / ADAGP 
Figure 47

Ce corpus de 526 verrières propose 240 verrières ornementales et 286 verrières figurées (sans compter les verrières de Mauméjean à la chapelle Sainte-Thérèse-de-l'Enfant-Jésus et à Notre-Dame-du-Bon-Conseil). Parmi ces 286 verrières figurées, on trouve 48 verrières archéologiques à compartiments légendaires, 128 verrières ornées de grands personnages (221), dont 38 surmontent de petites scènes légendaires traitées en grisaille, et 110 verrières montrant des scènes légendaires inscrites dans des niches (127), dont 37 verrières-tableaux stricto sensu ${ }^{106}$. Ce très petit nombre s'explique par le prix de revient trop élevé de celles-ci pour la majorité des communautés religieuses. Les rares verrièrestableaux recensées ont été financées soit par des donateurs aisés, telle la clientèle nantie de la maison de santé des Sœurs de Sainte-Marie-de-la-Famille ou la famille de Chambrun 
à l'hôtel de Bourbon-Condé, soit par de riches communautés comme les Jésuites à l'ancienne École Sainte-Geneviève (Notre-Dame du Liban). Pour les mêmes raisons, le petit nombre de verrières légendaires est bien inférieur à celui des verrières à grands personnages.

Figure 51 ou vitrail-tableau (néo-XVI ${ }^{\mathrm{e}}$ ), a été conceptualisée à la fin du $\mathrm{XIX}^{\mathrm{e}} \mathrm{s}$. sous la plume d'Édouard Didron et reprise par Jean Taralon en $1958^{107}$. La terminologie a évolué depuis : désormais le vitrail dit « archéologique » sous-entend la copie servile du XIII ${ }^{\mathrm{e}}$ s., tandis que l'inspiration des $\mathrm{XIV}^{\mathrm{e}}$, $\mathrm{XV}^{\mathrm{e}}$ et $\mathrm{XVI}^{\mathrm{e}}$ siècles est désignée alors par l'expression "vitrail historiciste $»^{108}$. Cette opposition entre vitrail archéologique et vitrail-tableau n'est pas catégorique, car on a vu des peintres verriers capables d'associer un carton néo-XIII ${ }^{\mathrm{e}}$ pour les parties décoratives à un carton néo-XVI ${ }^{\mathrm{e}}$ pour les parties figurées à l'intérieur d'une même verrière. De nombreux anachronismes apparaissent dans le choix stylistique de la verrière par rapport à l'architecture néogothique et même dans l'harmonisation des styles à l'intérieur de la même verrière ${ }^{109}$. À Saint-Jean-Baptiste-de-Belleville, force est de constater de flagrants anachronismes dans les médaillons perlés néo-XIII ${ }^{\mathrm{e}}$ des collatéraux, parmi lesquels se trouvent représentés saint François-Xavier (fig. $\mathbf{n}^{\circ}{ }^{51}$ ) ou le cardinal Borromée. Inversement, un très bel encadrement néo-Renaissance entoure de grandes figures assez modernisantes de Didron à Sainte-Rosalie. La plupart du temps, des motifs d'architecture "historicistes » encadrent un "tableau»: c'est le cas à SaintAndré-de-l'Europe où la verrière de l'Église se présente sous un double-dais néo-XV ${ }^{e}$, à l'église Saint-Eugène, dont les grandes scènes-tableaux des tribunes sont abritées sous des dais néo-XIII ou à la chapelle Sainte-Marie-de-la-Famille, pour laquelle Champigneulle a choisi le néo-XIVe afin d'encadrer des verrières-tableaux historiques. Émile Hirsch a opté pour des verrières mixtes à la chapelle de Bourbon-Condé, dans lesquelles un seul registre est traité en vitrail-tableau (fig. $\mathbf{n}^{\circ} \mathbf{5 2}$ ) et le reste en vitrail « historiciste »; les bordures sont de style néo-XIII autour de scènes ou personnages néo-Renaissance.

Figure 52

\section{[Image non convertie]}

Création du ciel et de la terre, de la lumière et des ténèbres, Noé, un roi, chœur de la chapelle de BourbonCondé, par Charles-Émile Hirsch, 1884

Phot. Jean-Bernard Vialles, 2007. (c) Région Île-de-France-Inventaire général / ADAGP

Figure 53

[Image non convertie]

Saint Louis, collatéral nord de la chapelle Sainte-Jeanne-d'Arc, vers 1913

Phot. Jean-Bernard Vialles, 2008. @ Région Île-de-France-Inventaire général / ADAGP 
Les encadrements d'architecture sont de manière générale des emprunts au XIII ${ }^{e}$ siècle (chapelle Notre-Dame-des-Anges, chapelle de Bourbon-Condé, Saint-Eugène, SaintJoseph-Artisan, chapelle des Sœurs de Saint-Joseph-de-Cluny, Saint-Jean-Baptiste-deBelleville), au XIVe s. (Notre-Dame du Liban, chapelle Sainte-Marie-de-la-Famille, SainteClotilde), ou au XV' siècle (chapelle Sainte-Jeanne-d'Arc (fig. $\mathbf{n}^{\circ}$ 53).

Les verrières à compartiments, qui se lisent traditionnellement de bas en haut et de gauche à droite ${ }^{110}$, ont le plus souvent pour thèmes les Vies de la Vierge, de Jésus, de saint Joseph et de saint Louis (à Sainte-Clotilde). Les baies hautes sont réservées aux grandes figures de saints du Moyen Âge ou des époques plus récentes, à l'exception, comme nous l'avons déjà signalé, de Sainte-Clotilde, de Saint-Bernard-de-La-Chapelle et de Saint-JeanBaptiste-de-Belleville dont les verrières hautes de la nef présentent des scènes inscrites sous des dais à la manière des "litres" médiévales, et de grandes figures d'apôtres inscrites dans des médaillons perlés (fig. $\mathbf{n}^{\circ}$ 54). 240 verrières ornementales ont été recensées. Leur présence massive est due, rappelons-le, à un moindre coût de fabrication dû aux nouvelles techniques d'impression des motifs répétitifs constitutifs (motifs végétaux et « cages à mouches »). Rompues de points ou de fermaillets de couleur, elles sont généralement composées de filets de couleurs formant des tracés géométriques copiés sur des modèles néo-XIII ${ }^{\mathrm{e}}$. Les plus anciennes de notre corpus ont été posées à la chapelle Notre-Dame-du-Bon-Secours vers 1843-1844, à Sainte-Clotilde dans les années 1850, à la chapelle de patronage des Jeunes-de-Saint-Vincent-de-Paul vers 1856. Les verrières hautes de Saint-Bernard-de-La-Chapelle (1861 par Gsell-Laurent) sont particulièrement remarquables, composées de filets et de fermaillets de couleurs vives à partir de cartons identiques. Celles de Saint-Ignace, composées de motifs végétaux de couleur dues également à Gsell et Laurent vers 1858, laissent filtrer une lumière douce (fig. $\mathbf{n}^{\circ}$ 55).

\section{Figure 54}

\section{[Image non convertie]}

Saint Jean-Baptiste et les Apôtres Jacques le Majeur, Paul, André, verrière du chœur de Saint-JeanBaptiste-de-Belleville, par Auguste de Martel, 1863, d'après un carton de Louis-Charles-Auguste Steinheil

(c) Martin Argyroglo Callias Bey, 2008

\section{Figure 55}

\section{[Image non convertie]}

Verrières ornementales, nef de la chapelle Saint-Ignace, par Johann-Gaspard-Julius Gsell et Émile Laurent, vers 1858

(c) Martin Argyroglo Callias Bey, 2008

\section{La technique}

131 Le vitrail néogothique annonce le retour à la couleur : grâce à la redécouverte du procédé de fabrication du verre rouge doublé, par Bontemps à la Manufacture de Choisy en 1826, l'on put désormais fabriquer du vitrail « archéologique ». Un retour aux procédés anciens s'avéra nécessaire pour maintenir la tradition face aux essais d'émaux faits à Sèvres et aux premières expériences de verrières peintes à la manière de tableaux. La vitrerie de 
l'église Saint-Jean-Baptiste-de-Belleville, réalisée vers 1863 par Auguste de Martel à partir des cartons de L.-A. Steinheil, se présente comme un manifeste pour le vitrail purement néo-XIII ${ }^{\mathrm{e}}$ voire néo-XII ${ }^{\mathrm{e}}$. On $\mathrm{y}$ trouve un souci archéologique, à la fois dans le développement de l'iconographie bien maîtrisée par Steinheil (Vies de la Vierge et du Christ , apôtres, vie des deux saints Jean, scènes de l'Ancien Testament, figures de saints), dans la typologie variée des verrières à compartiments, à grands personnages ou à scènes sous dais (fig. $\mathbf{n}^{\circ}$ 56), et dans les techniques mises en œuvre. La tradition médiévale des barlotières forgées à la forme des compartiments y est respectée tout comme à SainteClotilde, pour les médaillons ronds, quadrilobés, polylobés ou dodécagonales posés par Laurent-Gsell dans les chapelles absidiales, ou à Saint-Eugène (par Lusson) ${ }^{111}$ (fig. $\mathbf{n}^{\circ}$ 57) et à Saint-Ignace (par Laurent-Gsell).

Figure 56

\section{[Image non convertie]}

Péché originel, nef de Saint-Jean-Baptiste-de-Belleville, par Auguste de Martel, vers 1863, d'après un carton de Louis-Charles-Auguste Steinheil

(C) Martin Argyroglo Callias Bey, 2008

Figure 57

[Image non convertie]

Barlotières métalliques, façade de Saint-Eugène, 1854-1855. Blondel, Nicole. LE Vitrail. VocABuLAIRE TYPOLOgIQUE ET TECHNIQUE. Paris : Imprimerie nationale, 1993, p. 132 fig. 231

Repro. Martine Callias Bey, 2008. (C) Centre André Chastel

134 L'alternative au vitrail purement archéologique nous vaut des exemples d'une grande maîtrise technique, autant dans la pose de la grisaille appliquée en plusieurs couches et cuite plusieurs fois ${ }^{112}$, l'emploi de grisailles colorées et de nombreux émaux, que dans l'association de ces deux systèmes de coloration ${ }^{113}$, et dans la gravure au sable ou à l'acide 114. La technique traditionnelle du pochoir utilisée pour reproduire un même motif à l'infini, est encore employée à Sainte-Clotilde pour les fonds de grisaille des verrières des chapelles du chevet ${ }^{115}$.

Figure 58

\section{[Image non convertie]}

Déploration sur le corps du Christ, Pentecôte, chœur de Saint-Jean-Baptiste-de-Belleville, par Auguste de Martel, 1863, d'après un carton de Louis-Charles-Auguste Steinheil

(C) Martin Argyroglo Callias Bey, 2008

Mais, afin de répondre à une demande considérable, des recherches aboutissent bientôt à de nouveaux procédés - pas toujours aisés à reconnaitre - pour réaliser les parties décoratives répétitives ; les bordures, les fonds ou les motifs de grisailles végétales sont désormais sérigraphiés ou imprimés, par exemple dans les verrières de Maréchal à Sainte-Clotilde ${ }^{116}$ ou dans celles de Laurent-Gsell à Saint-Bernard-de-La-Chapelle. La grande taille des pièces de verre, désormais courante, permet de larges à-plats colorés, par exemple dans les verrières hautes du chœur de Saint-Jean-Baptiste-de-Belleville ou de Saint-Bernard-de-La-Chapelle. (fig. $\mathbf{n}^{\circ}$ 58) 
137 À défaut de portraits-photos, on trouve dans ces verrières des visages fortement individualisés, que ce soit les évangélistes, les apôtres et autres saints de Saint-Bernardde-La-Chapelle, les grandes figures de prophètes de Sainte-Clotilde ${ }^{117}$ ou encore les portraits des fondateurs d'ordres à Sainte-Rosalie et à la chapelle Sainte-Marie-de-laFamille.

138 La production s'est-elle industrialisée après $1870-1880^{118}$ ? Même s'il est vrai que les procédés de reproduction des motifs répétitifs permettent la multiplication rapide de verrières ornementales, il demeure que la variété des autres verrières figuratives, dont pas une n'est la copie d'une autre, le remploi de cartons concernant plutôt les parties décoratives et architecturales, exprime bien le fait que le peintre verrier reste un artiste avant d'être un chef d'entreprise.

\section{La protection des vitraux du $\mathrm{XIX}^{\mathrm{e}}$ siècle}

139 Ce patrimoine est en danger, tant du fait de sa fragilité ou de ses altérations que de la méconnaissance dont il est l'objet, parce que le recul est encore insuffisant pour l'apprécier au même titre que le vitrail " ancien », et parce qu'il semble peu digne d'être sauvegardé. À Paris, trois chapelles néogothiques seulement sont protégées au titre des Monuments historiques : la chapelle Notre-Dame-des-Anges ${ }^{119}$ et la chapelle de l'hôtel de Bourbon-Condé ${ }^{120}$ et parmi les églises, seule l'église néogothique Saint-Eugène est classée $\mathrm{MH}^{121}$. La Ville de Paris possède aussi son système de gestion et de protection des édifices cultuels et historiques aux titres du PSMV pour Sainte-Clotilde et sa chapelle des catéchismes, et du PLU pour Saint-Bernard-de-la-Chapelle ${ }^{122}$.

140 Les vitraux du XIX ${ }^{e}$ siècle ont été longtemps classés «immeubles par destination", comme les boiseries ou les peintures murales, et c'est n'est que depuis les années 1970 qu'ils sont protégés, le plus souvent inscrits, exceptionnellement classés au titre des Monuments historiques. Aucune mesure de ce type ne protège les vitraux néogothiques de Paris. Or il y a urgence à le faire, sachant que des ensembles entiers de vitraux du XIX ${ }^{\mathrm{e}}$ ont déjà disparu comme ceux de Notre-Dame-du-Perpétuel-Secours dans le $\mathrm{XI}^{\mathrm{e}}$ arrondissement de Paris et de Notre-Dame-du-Saint-Sacrement, rue Cortambert dans le $\mathrm{XVI}$.

141 La faible résistance des fidèles au froid et le besoin de chauffer davantage a été depuis les années 1950 la cause de nombreuses destructions ou transformations de chapelles par la pose de niveaux intermédiaires. Depuis les années 1960, des chapelles anciennes, et notamment celles du XIX ${ }^{e}$ siècle ont totalement disparu ou ont été remplacées par des chapelles plus récentes construites à l'intérieur de programmes immobiliers rentables pour les communautés ( 38 sans distinction de style ni d'époque de construction). Ces opérations se poursuivaient encore à la fin du $\mathrm{XX}^{\mathrm{e}}$ siècle, l'une des parades étant de faire protéger le bâtiment au titre des monuments historiques ${ }^{123}$.

142 L'état sanitaire de ces verrières n'est pas spécifiquement alarmant, encore qu'inégal ; les besoins de restaurations s'avèrent équivalents à ceux qui concernent le vitrail ancien, à savoir remises en plomb ou collages, comblements de lacunes, pose de protections extérieures, "refixages» de grisaille, nettoyages, masticages, etc. Nous avons en effet constaté quelques bris de verres, des trous, des verres manquants ${ }^{124}$, des grisailles effacées, surtout sur les verres de couleur chair ${ }^{125}$. Mais globalement, les verres 
présentent peu d'altérations, du fait de la stabilité de leur composition; la plupart des verrières sont protégées par des grillages extérieurs.

La question de la reprise des restaurations se pose maintenant, notamment pour les verrières de Sainte-Clotilde, qui ont été mal restaurées en 1873 par le vitrier Denis ${ }^{126}$. Signalons que la Ville de Paris procède régulièrement à des travaux de restaurations sur les verrières des ses églises (Saint-Jean-Baptiste-de-Belleville, Saint-Eugène, SainteClotilde, etc.), et que certaines communautés ont à cœur de préserver leur patrimoine, comme à la chapelle Sainte-Jeanne-d'Arc (restauration des vitraux en 1986, par l'atelier de la Vieille Maison aux Loges-en-Josas, Yvelines), à la chapelle Notre-Dame-des-Anges, où la rose de la Vierge a été restaurée en 1991, à la chapelle Notre-Dame-du-Bon-Secours en 1999, etc.

\section{En guise de conclusion}

Le vitrail néogothique a eu, en son temps, ses admirateurs et ses détracteurs : Didron n'a eu de cesse d'encenser Antoine Lusson après la réalisation de sa verrière de la Vie de la Vierge à la Couture du Mans en $1844^{127}$, tandis qu'Émile Thibaud émettait déjà en 1838 quelques réserves: "Mettons le plus de discernement possible dans les emprunts que

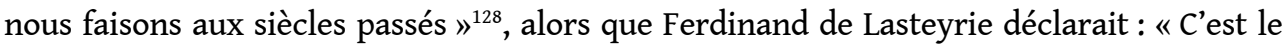
style en honneur au XIII ${ }^{e}$ et tout au plus au XIV ${ }^{e}$ siècle, le plus décoratif qui ait jamais existé et le plus facile à reproduire au point de vue de l'art et par la suite le moins coûteux $»^{129}$; Lucien Magne, soixante-dix ans plus tard, rejetait en bloc le vitrail archéologique: "Comment a-t-on pu pendant un siècle se contenter de cette similidécoration qui a déshonoré les églises ? »...130 en lui préférant les Luc-Olivier Merson (1846-1920), J.P. Laurens (1838-1921), Ehrmann (1833-1910), Jac Galland, E. Grasset (1841-1917), F. Gaudin ou Tournel.

145 Le but de cet inventaire sommaire est de faire prendre conscience aujourd'hui de la valeur de ce patrimoine du XIX siècle qui souffre encore d'un certain a priori de médiocrité... Le vitrail du XIXe siècle est couramment jugé comme un art semi-industriel et son esthétique n'est pas vraiment au goût du jour. Il est donc urgent de sensibiliser le public et d'éviter que l'on fasse encore disparaitre des vitraux du XIXe siècle liés au sort d'édifices dont l'avenir pourrait un jour dépendre d'un mouvement d'« humeur »... L'époque est bien révolue où l'on transportait pierre par pierre une chapelle, NotreDame-de-l'Assomption, de la rue de Varenne à Passy, c'était en 1881... Le XIX ${ }^{e}$ siècle a malheureusement subi le mépris affiché des rénovateurs de l'art sacré, jusqu'aux années 1980 ; l'exemple le plus médiatique de ce désaveu a été le remplacement entre 1964 et 1969 à Saint-Séverin des huit verrières de Hirsch et de Tournel par Bazaine (1904-2001). D'autre part, on ne compte plus les vitraux qui ont disparu faute de réparations. Par un juste retour des choses, s'amorce aujourd'hui un changement d'état d'esprit vis-à-vis de l'art religieux du XIX ${ }^{e}$ siècle en général, considéré désormais comme le témoignage d'une période passionnante.

Figure 59

[Image non convertie]

Sainte Jeanne d'Arc à l'écoute de saint Michel, collatéral sud de Notre-Dame-du-Liban, par Charles-Émile Hirsch, 1899

Phot. Philippe Fortin, 2005. (c) Inventaire général / ADAGP 
«Le vitrail archéologique : fidélité ou trahison du Moyen Âge? ?, la question se posait en $1986 \ldots{ }^{131}$. Nous répondrons aujourd'hui que ces vitraux ne sont pas des pastiches, mais la traduction d'un choix et d'un compromis de la part des artistes du XIX ${ }^{\mathrm{e}}$ s. entre «l'archéologique », « l'archaïsant » (libre interprétation du Moyen Âge) et la création pure, étroitement liés dans la recherche d'un nouveau langage. Les choix stylistiques entre «l'archéologique ", l'« historiciste » et le tableau, ne sont pas tranchés; concluons avec Bruno Foucart que l'éclectisme est un style en lui-même, complexe et créatif, riche d'un désir de renouvellement, que ce soit en matière d'architecture ou de décor religieux ${ }^{132}$. (fig. $\mathbf{n}^{\circ}$ 59) Remarquons que pour la première fois dans l'histoire de la peinture sur verre religieuse, il n'existe plus, dans la seconde moitié du XIX ${ }^{e}$ siècle, de cohérence entre le style de référence du décor vitré et le style adopté pour l'architecture, et que le vitrail néogothique trouve parfaitement sa place dans une architecture flamboyante ou inversement. Nous verrons par ailleurs que cette observation est aussi valable dans le cadre des édifices néo-romans, néo-byzantins ou néoclassiques.

Figure 60

\section{[Image non convertie]}

Sainte Catherine, sainte Foi (détail), nef de la chapelle Notre-Dame-des-Anges, par Joseph Villiet, 1866 Phot. Philippe Fortin, 2006. (c) Inventaire général / ADAGP

149 À la fin de cet inventaire, force est de constater la prédominance des vitraux à caractère gallican et de style « archéologique » ou pour le moins « historiciste ». Quelques édifices montrent cependant une certaine distorsion entre l'architecture bien marquée néo-XIII ${ }^{e}$ et une iconographie nouvelle, c'est le cas des verrières de la chapelle Sainte-Marie-de-laFamille, de Notre-Dame du Liban, de la chapelle de Bourbon-Condé et de Saint-André de l'Europe, réalisées respectivement par Champigneulle et la Société artistique de peinture sur verre, Émile Hirsch et Georges-Claudius Lavergne, formés l'un par Delacroix (1798-1863) et H. Flandrin, l'autre par son père Claudius, lui-même élève d'Ingres et fervent admirateur des Nazaréens. L'apport de ceux-ci ne concerne pas seulement l'iconographie, mais surtout la manière de peindre, jouant de toutes les possibilités techniques de la peinture sur verre, anciennes et nouvelles, développées au cours du XIX ${ }^{\mathrm{e}}$ siècle (fig. $\mathbf{n}^{\circ} \mathbf{6 0}$ ).

150 Paris a joué un rôle déterminant dans la renaissance du vitrail dans le premier tiers $d u$ $\mathrm{XIX}^{\mathrm{e}}$ siècle, un rôle d'initiateur et de ferment propice au développement de nombreux ateliers... La tradition du vitrail médiéval a perduré longtemps, malgré de fortes avancées vers des nouveautés autant iconographiques que stylistiques. Paris s'est révélé garant d'une certaine tradition, moins novateur qu'on aurait pu le croire, au moins dans les édifices néogothiques... les nouveaux dogmes s'y affichent discrètement, contrairement à la province et même à la banlieue, comme a pu le montrer la synthèse réalisée par Laurence de Finance ${ }^{133}$. Cette constatation pourrait évoluer avec l'étude globale que nous poursuivons sur les verrières du XIX ${ }^{e}$ siècle conservées dans les édifices religieux chrétiens de Paris ${ }^{134}$.

151 Les surprises réservées par cette première recherche montrent de façon évidente la qualité du travail des peintres verriers parisiens, à la fois peintres, techniciens du vitrail, iconographes... Que ce soit à propos de Saint-Jean-Baptiste-de-Belleville et de SaintBernard-de-La-Chapelle (fig. $\mathbf{n}^{\circ}{ }^{61}$ ) pour la part strictement archéologique, ou de NotreDame du Liban (fig. $\mathbf{n}^{\circ} \mathbf{6 2}$ ) et de la chapelle Notre-Dame-des-Anges pour leur apport 
stylistique, la peinture sur verre des édifices néogothiques parisiens apporte de nombreux démentis aux préjugés qui peuvent encore exister sur la valeur de ce patrimoine, dans l'ensemble méconnu.

Figure 61

[Image non convertie]

Saint Barthélémy, collatéral sud de Saint-Bernard-de-La-Chapelle, par Eugène Oudinot, vers 1861

(C) Martin Argyroglo Callias Bey, 2008

Figure 62

[Image non convertie]

Le voyage des Mages, triforium du chœur de Notre-Dame-du-Liban, par Charles-Émile Hirsch, 1899

Phot. Philippe Fortin, 2005. (c) Inventaire général / ADAGP

\section{NOTES}

1. Nous excluons de cette première étude les édifices parisiens (églises et chapelles) antérieurs au $\mathrm{XIX}^{\mathrm{e}}$, les édifices parisiens (églises et chapelles) du XIX ${ }^{\mathrm{e}}$ qui ne sont pas néogothiques, les édifices néogothiques qui ne conservent plus leurs vitraux d'origine, ainsi que les lieux de culte des autres religions. Sur 70 chapelles parisiennes datant du XIX ${ }^{\mathrm{e}}$ siècle, 21 sont de style néogothique (16 avec leurs vitraux d'origine), 10 chapelles néo-romanes (dont 4 avec leurs vitraux), une chapelle néo-Renaissance (avec vitraux), 4 chapelles romano-byzantines (dont 2 avec vitraux), 4 chapelles de plan basilical romain (dont 3 avec vitraux), deux chapelles de style néo-classique (dont une avec vitraux), une chapelle de style éclectique (avec vitraux). Par ailleurs, nous avons recensé dans Paris intra-muros, en plus des 70 chapelles mentionnées, 39 chapelles disparues avec leurs vitraux et 66 chapelles existantes sans vitraux.

2. Les Archives des Monuments historiques, dossier Chapelle des Sœurs de Saint-Vincent-dePaul, cote 1997/018/0023, gardent un courrier de M. Jean-Louis Hannebert, architecte du patrimoine, envoyé au Conservateur régional des monuments historiques d'île-de-France à la date du 3 juin 1994, signalant qu'il avait dû autoriser la démolition de trois chapelles du XIX ${ }^{\mathrm{e}}$ : la Procure des Petits Frères de Jésus, 3 rue Pierre Leroux, la chapelle des Dominicaines de sainte Catherine de Sienne, 64 rue des Plantes et la chapelle du couvent des Franciscains, 81 rue Falguière ; en revanche il avait fait protéger et restaurer les chapelles du 29 rue Las Cases et du 391 rue de Vaugirard et comptait s'opposer à la démolition de la chapelle des Sœurs de SaintVincent-de Paul, 7 rue Cler. "Tous les autres édifices de la même période sont menacés... » concluait-il. Plus précisément les chapelles de la rue d'Auteuil, Sainte-Bernadette, des QuinzeVingt, l'église luthérienne Saint-Jean, etc. (Archives de la Médiathèque de l'architecture et du patrimoine, 97/18/36, 81/75-16, 81/75-07, 81/75-12, etc.). François Macé de Lépinay, dans un courrier à l'attention de Christian Pattyn, daté du 5/2/82, déplore la démolition des chapelles de Notre-Dame-de-Sion et des Petites-Sœurs-des-Pauvres, rue Notre-Dame-des-Champs dans le $\mathrm{VI}^{\mathrm{e}}$ arrondissement, dans les années 1970 (dossier COARC de la Chapelle Notre-Dame-des-Anges). 
3. Par exemple la chapelle néogothique de l'ancien couvent du Sacré-Cœur installé dans l'Hôtel de Biron (Musée Rodin), transformée vers 1955 en salle d'exposition d'où furent déposées 5 verrières d'Emile Hirsch datées de 1876 (saintes Cécile, Philomène, Catherine, Julie, Geneviève), entreposées actuellement au dépôt de la Ville de Paris.

4. De la révolution à 1920. Le Vitrail français, 1958, p. 273-292.

5. Foucart, Bruno. La fortune critique d'Alexandre Lenoir et du premier musée des Monuments français, L'Information d'Histoire de l'Art, 1969-5, p. 223-232. Comment peut-on aimer une église du XIX ${ }^{e}$ siècle ou de la réhabilitation du pastiche, Revue des Monuments Historiques, $t$. XX, fasc. 1, 1974, p. 64-71. Hamon, Françoise. L'architecture religieuse au XIX ${ }^{\mathrm{e}}$ siècle, entre éclectisme et rationalisme. Paris: PUPS, 2006. Voir aussi l'ouvrage collectif, Deux siècles précurseurs, Essais et Mélanges. Paris : Norma Editions, 2008. Leniaud, Jean-Michel. JeanBaptiste Lassus (1807-1857), ou le Temps retrouvé des cathédrales. Paris, 1980, p. 167-168. Les constructions d'églises sous le Second Empire: architecture et prix de revient, Revue d'Histoire de l'Église de France, $n^{\circ}$ 65, 1979, p. 268-278, 279. Les prêtres architectes, Les prêtres archéologues, in Bouchon, Chantal, Brisac, Catherine, Chaline, J.-C. Ces églises au XIX $\mathrm{X}^{\mathrm{e}}$ siècle, Amiens, 1993, p. 90-94, 104-106. Les cathédrales du XIX ${ }^{\mathrm{e}}$ siècle : étude du service des édifices diocésains, 1993. Quelques hypothèses sur l'aménagement intérieur de l'édifice cultuel au XIX ${ }^{\mathrm{e}}$ siècle, Rêves de chrétienté... Actes du colloque de Louvain-la-Neuve, nov. 1999, Paris, Louvain, 2001, p. 304-314. La révolution des signes: l'art à l'église 1830-1930, Paris, 2007. Des bibliographies plus complètes figureront dans le Recensement des vitraux du XIX ${ }^{\mathrm{e}}$ siècle des édifices religieux parisiens, à paraître en 2010. Cette précision s'applique aux notes bibliographiques suivantes.

6. Brisac, Catherine. Le vitrail «archéologique» en France au XIX ${ }^{\mathrm{e}}$ siècle : modèles et transpositions, Il neogotico in Europa nei secoli $\mathbf{X I X}^{\mathrm{e}}-\mathbf{X X}^{\mathrm{e}}$, Pavie, 1985, réed. Milan, t. 2, 1988, p. 201-211. Bouchon, Chantal. Le vitrail au XIX ${ }^{\mathrm{e}}$ siècle : état des travaux et bibliographie, Revue de l'Art, $n^{\circ} 72,1986$, p. 83-89. Une manufacture de vitrail au XIX ${ }^{\mathrm{e}}$ siècle : A. Lusson, Cat. exp. Le vitrail à Lisieux, Musée de Lisieux, 1987. Le vitrail, in Bouchon, Chantal, Brisac, Catherine, Chaline, J.-C., Ces églises au XIX ${ }^{\mathrm{e}}$ siècle, Amiens, 1993. Bouchon, Chantal. Faits contemporains dans le vitrail du XIX ${ }^{\mathrm{e}}$ siècle et Les verrières de Jeanne d'Arc. Exaltation d'un culte à la fin du XIX siècle, Annales de Bretagne et des Pays de la Loire, 1986, t. 93, nº 4, p. 411-417, 419-443. La Renaissance du vitrail : Eustache-Hyacinthe Langlois, Etudes normandes, $\mathrm{n}^{\circ} 4$, 1989, p. 35-40. Le $\mathrm{XIX}^{\text {ème }}$ siècle dans le $\mathrm{XV}^{\text {ème }}$ arrondissement de Paris, Bulletin de l'Association pour l'étude du $X_{X}{ }^{\text {ème }}$ siècle français, 1992. Le vitrail religieux sous le Second Empire, Le vitrail en Picardie et dans le nord de la France aux XIX ${ }^{\mathrm{e}}$ et $\mathrm{XX}^{\mathrm{e}}$ siècles, Amiens : éd. Encrage, 1995, p. 9-19. Une approche du vitrail (1800-1850), Cat. exp. Le vitrail au XIX ${ }^{\mathrm{e}}$ siècle et les ateliers manceaux, Le Mans, collégiale Saint-Pierre-la-Cour, Le Mans : éd. Cénomane, 1998, p. 21-37.

7. Callias Bey, Martine, CHaussé, Véronique, Finance, Laurence (de), Gatouillat, Françoise. Les ateliers, et Enquête sur les peintres verriers du XIX ${ }^{\mathrm{e}}$ siècle ayant travaillé en France, Revue de l'Art, $n^{\circ} 72$, 1986, p.55-56, 67-90 (Voir sur le site www.culture.gouv.fr/culture/inventai/ patrimoine/ la liste des Auteurs dans Vocabulaires : seules les lettres A et B sont intégrées). Voir aussi Chaussé, Véronique. Orientations bibliographiques sur le vitrail français au XIX ${ }^{\mathrm{e}}$ siècle depuis 1958, Vitrea, $n^{\circ} 3,1989$, p. 28-33.

8. Perrot, Françoise. « La restauration des vitraux », « Viollet-le-Duc et le vitrail au XIX ${ }^{\mathrm{e}}$ siècle », "Viollet-le-Duc et les peintres verriers », Viollet-le-Duc, Paris, Galeries nationales du GrandPalais, 19 février 1980-5 mai 1980, Paris : RMN, 1980, p. 174-175, 282-283, 292-294. Blondel, Nicole, Bracco, Patrick. Viollet-le-Duc et la Manufacture royale de Sèvres, ibidem, p. 284-287. Viollet-leDuc, Actes du colloque international tenu à Paris, Grand Palais, printemps 1980, Paris : Nouvelles éditions latines, 1982.

9. Archives de Catherine Brisac à la Médiathèque de l'architecture et du patrimoine, cote 1993/017. 
10. Costa, Vanina. Étude préliminaire à l'inventaire des vitraux du XIX ${ }^{\mathrm{e}}$ et première moitié du xx ${ }^{\mathrm{e}}$, dir. D. Hervier, Paris, 1987 (dactyl., DRAC Ile-de-France).

11. Groupe de recherche en iconographie moderne et contemporaine de l'Ouest, fondé en 1978 par Mme Michèle Ménard, professeur à l'Université du Maine au Mans ; le GRIMCO organisa des rencontres annuelles au Mans et dans plusieurs villes de France.

12. Bouchon, Chantal, Brisac, Catherine, Vinsot, Jeanne. Les vitraux de la basilique SainteClotilde à Paris. Imprimerie alençonnaise, 1987.

13. Blondel, Nicole, Bracco Patrick. Le vitrail religieux au XIX ${ }^{\mathrm{e}}$ siècle, Espace, église, arts, architectures, $\mathrm{n}^{\circ} 9,1980$, p. 30-33. Un art retrouvé: le vitrail à Sèvres au $\mathrm{XIX}^{\mathrm{e}}$ siècle, L'Estampille, n` 118, 1980, p. 10-19.

14. Cabezas, Hervé. La politique nationaliste de l'Église catholique française sous la III ${ }^{\mathrm{e}}$ République: l'exemple de Notre-Dame-des-Vertus d'Aubervilliers, Revue d'archéologie moderne et d'archéologie générale (RAMAGE), nº 5, 1987, p. 191-236. Du vitrail archéologique, RAMAGE, $n^{\circ}$ 6, 1988, p. 107-126. Tradition et nouveautés du vitrail français au XIX ${ }^{\mathrm{e}}$ siècle, Vitrea, $n^{\circ} 3,1989$, p. 3-11. Recherches sur la renaissance du vitrail peint à Paris entre 1800 et 1830, Les arts du verre, Histoire, technique et conservation. Journées d'études de la S.F.I.I.C., Nice, 17-19 sept. 1991, Champs-sur-Marne, p. 35-59. L'atelier de vitraux parisien Billard-Laurent-Gsell (1838-1892), Cahiers de la Rotonde, $n^{\circ} 17,1996$, p. 163-173. Les vitraux de la basilique de SaintDenis au XIX ${ }^{\mathrm{e}}$ siècle, Vitrea, vol. 9, 1996, p. 23-67.

15. Gatouillat, Françoise. Modèles, copies, répliques dans le vitrail du XIX ${ }^{\mathrm{e}}$ siècle, Vitrea, 1989, n -3, p. 12-14. Les vitraux du XIX ${ }^{\mathrm{e}}$ siècle, problématiques de sauvegarde, Regards sur le vitrail, Actes Sud, Mayenne, 2002, p. 36-43. Un don de l'empereur d'Autriche : les verrières viennoises de Saint-Joseph-Artisan, Paris, Monumental, 2004, n 1, p. 28-29.

16. Luneau, Jean-François. Vitrail archéologique, vitrail-tableau. Chronique bibliographique, Revue de l'Art, $n^{\circ}$ 124, 1999, p. 67-78. Modèles et cartons au XIX siècle : un enseignement pour la connaissance des pratiques anciennes ?, Vitrail et Arts graphiques, $\mathrm{XV}^{\mathrm{e}}-\mathrm{XVI}^{\mathrm{e}}$ siècles, Paris, Cahiers ENP, $\mathrm{n}^{\circ}$ 4, Paris, 1999, p. 117-133. Félix Gaudin, peintre-verrier et mosaïste (1851-1930), Clermont-Ferrand: Presses universitaires Blaise-Pascal, 2006. À la recherche des secrets perdus. Les ouvrages du XIX ${ }^{\mathrm{e}}$ siècle sur le vitrail, Le vitrail et les traités du Moyen Âge à nos jours, Berne : Peter Lang, 2008, p. 261-276.

17. Pillet, Élisabeth. Prosper Lafaye (1806-1883), peintre et peintre verrier. Entre création artistique et restitution archéologique, Mémoire de D.E.A., EPHESS, 1996. La restauration des vitraux des églises paroissiales de Paris de la Révolution à 1880, Thèse, EPHESS, 2005 (dir. J.M. Leniaud).

18. Finance, Laurence (de). Le vitrail religieux, in Finance, Laurence (de) et alii. Un patrimoine de lumière 1830-2000, Verrières des Hauts-de-Seine, Seine-Saint-Denis, Val-de-Marne, Paris : Monum, éd. du Patrimoine, 2003, p. 93-94.

19. Molette, Charles. Les archives de l'Église de France, Revue de l'Histoire de l'Église de France, t. LXVI, $n^{\circ}$ 176, janvier-juin 1980, p. 51-59. Barbiche, B., « AJOUTER LIEN SUR ARTICLE BARBICHE

20. Molette, Charles. Les archives de l'Église de France, Revue de l'Histoire de l'Église de France, t. LXVI, n. 19, p. 53-54.

21. Voir dans la base Mérimée: notice PA00085796. Voir dans la base Mémoire: image APMH00082673.

22. Voir dans la base Mérimée: notice PA00086250. Voir dans la base Mémoire: image AP56P00724, image APMH00014116, image APMH00014040.

23. Voir dans la base Mérimée : notice PA00088498.

24. Voir dans la base Mérimée : notice PA00088698.

25. Voir dans la base Mémoire : image APMH00071088.

26. Voir dans la base Mérimée : notice PA00088907. 
27. Ce dogme fut confirmé par Bernadette Soubirous elle-même, qui rapporta les mots de la Vierge lors de la $16^{\mathrm{e}}$ Apparition en 1858 : «La dame a dit : je suis l'Immaculée Conception ».

28. Pelletier, Denis. Les catholiques en France depuis 1815. Paris : La Découverte, 1997.

29. Finance, Laurence (de). Le vitrail religieux, in Finance, Laurence (de) et alii. Un patrimoine de lumière 1830-2000, Verrières des Hauts-de-Seine, Seine-Saint-Denis, Val-de-Marne, Paris : Monum, éd. du Patrimoine, 2003, p. 93-94.

30. Sauf les contemplatives et les missionnaires, interdites en 1809. Langlois, Claude. Les effectifs des congrégations féminines au XIX ${ }^{\mathrm{e}}$ siècle, Revue d'Histoire de l'Église de France, t. LX, $\mathrm{n}^{\circ} 164$, janvier-juin 1974, p. 39-64.

31. Statistique des congrégations autorisées. Paris: Bureau des Cultes, Impr. Nat., 1897. Langlois, Claude. Les effectifs des congrégations féminines au XIX ${ }^{\mathrm{e}}$ siècle, Revue d'Histoire de l'Église de France, t. LX, n 164, janvier-juin 1974, p. 41 n. 5.

32. Six nouvelles congrégations se créent par an entre 1820 et 1860 ; leur nombre s'accroît jusqu'à 1858, puis va en diminuant jusqu'à devenir nul après 1871 .

33. 130000 ou 150000 congréganistes en 1880 dont 105000 enseignants, dix fois plus qu'en 1808 . Voir Langlois, Claude. Les effectifs des congrégations féminines au XIX ${ }^{\mathrm{e}}$ siècle, Revue d'Histoire de l'Église de France, t. LX, nº 164, janvier-juin 1974, n. 24.

34. À hauteur de 105 millions de francs vers 1860.

35. Pour toutes références aux missions féminines, voir Dufourcq, Élisabeth. Les Aventurières de Dieu. Trois siècles d'histoire missionnaire française. Paris : J.-C. Lattès, 1993.

36. L'une des grandes figures de cette congrégation fut alors sœur Rosalie Rendu, très vénérée pour son rôle exemplaire auprès des plus pauvres (ouverture d'un dispensaire, d'une école, d'un orphelinat) et dans la création des Conférences Saint-Vincent-de-Paul avec Frédéric Ozanam; elle fut béatifiée par Jean-Paul II en 2003.

37. Cette communauté ouvre en 1867 l'orphelinat Saint-Charles au 310, rue de Vaugirard, sur un terrain s'étendant jusqu'à la rue Blomet, pour loger les enfants des victimes du choléra qu'elle avait recueillis.

38. (1839-1904). Elle fut béatifiée par le pape Jean-Paul II en 2002.

39. Finance, Laurence (de). Le vitrail religieux, in Finance, Laurence (de) et alii. Un patrimoine de lumière 1830-2000, Verrières des Hauts-de-Seine, Seine-Saint-Denis, Val-de-Marne, Paris : Monum, éd. du Patrimoine, 2003, p. 96.

40. La chapelle des Jeunes de Saint-Vincent-de-Paul fut ouverte en 1846. Voir LES EDIFICES NÉOGOTHIQUES PARISIENS ET LEURS VERRIERES - EGLISES ET CHAPELLES CATHOLIQUES, tableau infra.

41. La renaissance de la Compagnie de Jésus date de 1814 ; les Jésuites s'installent rue de Sèvres dès 1821 et ce n'est que 34 ans plus tard qu'ils entreprennent de construire cette grande chapelle. 42. Le décret d'expulsion de 1880 imposa aux autres de solliciter une demande d'autorisation; aucune des demandes de la part de congrégations féminines ne fut acceptée, en revanche cinq congrégations hospitalières masculines sur 60 demandes seront autorisées.

43. Par le biais de la "mainmorte", les congrégations s'étaient constitué un patrimoine considérable, leurs biens restant inaliénables du fait de la durée indéfinie des vœux, et non soumis aux droits de mutation.

44. Cependant, demeure la possibilité de financer sur fonds publics des aumôneries, créées au sein de services publics civils, écoles, hôpitaux, prisons, établissements militaires, permettant d'assurer le culte pour des personnes ne pouvant se déplacer.

45. Bercé, Françoise. Des Monuments historiques au Patrimoine du XVIII ${ }^{\mathrm{e}}$ siècle à nos jours ou « Les égarements du cœur et de l'esprit ». Paris : Flammarion, 2000, p. 24 et sq.

46. Leniaud, Jean-Michel. Les travaux paroissiaux au XIX ${ }^{\mathrm{e}}$ siècle : pour une maîtrise d'ouvrage, Revue d'Histoire de l'Église de France, n 190, t. 73, 1987, p. 53-59. 
47. Voir le Répertoire des architectes diocésains du XIX ${ }^{\mathrm{e}}$ siècle mis en ligne par Jean-Michel Leniaud : elec.enc.sorbonne.fr/architectes/.

48. Didron, Édouard. Instructions pour l'iconographie chrétienne, 1841. Iconographie chrétienne. Histoire de Dieu, 1844. Id., dans les Annales archéologiques, 1844-1872. Instructions pour la conservation et l'entretien des vitraux dans les cathédrales et les édifices diocésains, Annales archéologiques, t. IX, 1852, p. 85 (il signale l'ouverture de près de 200 chantiers d'églises néo gothiques en France).

49. Cité par Bruno Foucart. Le renouveau de la peinture religieuse en France (1800-1860). Paris, 1987, p. 61.

50. Voir son Dictionnaire du mobilier, Paris, 1863, et l'article "Restauration" dans son Dictionnaire raisonné de l'Architecture du xi ${ }^{\mathrm{e}}$ au xvi ${ }^{\mathrm{e}}$ siècle, Paris, 1854-1868.

51. Voir LES ÉDIFICES NEO-GOTHIQUES PARISIENS ET LEURS VERRIERES - EGLISES ET CHAPELLES CATHOLIQUES, tableau infra.

52. Texier, Simon. Les architectes entre audace et compromis, in Texier, Simon et alii. Églises parisiennes du XX $X^{\mathrm{e}}$ siècle, Paris : AAVP, 1996, p. 51.

53. Cabezas, Hervé. Les sept verrières anglaises commandées par le Comte de Chabrol pour deux églises de Paris (1825-1828) et leur influence sur la création française de vitraux, Bulletin de la Société de l'Histoire de l'Art français (année 1998), 1999, p. 235-272. Voir aussi Finance, Laurence (de). Chronologie de la renaissance du vitrail à Paris au XIX siècle: L'exemple de l'église Saint-Laurent. Paris : Ministère de la Culture et de la Communication, revue In situ n ${ }^{\circ} 9$, avril 2008 [date de consultation 27/03/2009].

54. Bouchon, Chantal. Une approche du vitrail (1800-1850), Le vitrail au XIX $\mathrm{X}^{\mathrm{e}}$ siècle et les ateliers manceaux, Le Mans : éd. Cénomane, 1998, p. 21-37.

55. Hérold, Michel. Les manuels de vitriers et de peintres sur verre (1828-1843) ou La bibliothèque de Bouvard et Pécuchet, Le vitrail et les traités du Moyen Âge à nos jours, Actes $\mathrm{du}$ XXIII $^{\mathrm{e}}$ colloque international du Corpus Vitrearum, Tours, 3-7 juillet 2006, Berne, 2008, p. 2431-259. Je remercie tout particulièrement Michel Hérold de m'avoir donné accès à sa documentation.

56. Brisac, Catherine, Leniaud, Jean-Michel. Adolphe Napoléon Didron ou les médias au service de l'art chrétien, Revue de l'Art, n 77, 1987, p. 359-372.

57. Voir Annales archéologiques, 1844, p.147-150, et Bulletin du Comité des Arts et monuments, 1844, t. III, p. 205.

58. Didron s'associa avec Émile Thibaud pour créer une manufacture de vitraux destinée à la mise en place des trois roses de Sainte-Clotilde (1849-1852). Voir Didron, Adolphe N. Création d'une manufacture de vitraux à Paris, Annales archéologiques, 1849, p. 352-356.

59. Lavergne, Georges Claudius. Gens de métier, La Vérité, 9 oct. 1893. Voir Luneau, JeanFrançois. Félix Gaudin, peintre-verrier et mosaïste (1851-1930). Clermont-Ferrand: Presses universitaires Blaise-Pascal, 2006, p.179-180, 219. L'auteur cite une enquête du ministère du Commerce et de l'Industrie datée de 1878 (Arch. Nat., F 12 3367) qui montre la diversité de ces ateliers dans leur organisation; les ateliers étaient situés à Montparnasse (29\%), à Montmartre $(13,5 \%)$ ou à Ménilmontant (13,5\%).

60. Bertrand, Ernest. Peinture sur verre. Notice sur les travaux de Messieurs VincentLarcher et Martin-Hermanowska, Troyes, 1845.

61. Leniaud, Jean-François. Le vitrail au XIX ${ }^{\mathrm{e}}$ siècle : sources et problèmes iconographiques, Revue d'Histoire de l'Église de France, t. LX-VII, n 178, 1981, p. 86.

62. Ces pratiques ont perduré au cours $d u X^{e}$ s. puisque la verrière d'axe de la chapelle SainteJeanne d'Arc a été enduite d'un badigeon grisâtre en 1960, afin d'en atténuer la luminosité à la demande des sœurs. À noter également qu'il existe encore des stores à la chapelle de la clinique Blomet. 
63. Cabezas, Hervé. Rideaux et vitraux, pour le confort des églises de Paris au XIX ${ }^{\mathrm{e}}$ siècle, RAMAGE, $n^{\circ} 10,1992$, p. 69-85.

64. Justement distinguée par l'archéologue François de Guilhermy, malgré le fait que «Les communautés religieuses de femmes se sont rétablies en grand nombre depuis un demi-siècle, et chacune s'est construit une chapelle. Mais ces oratoires, la plupart de dimensions très restreintes, n'ont rien qui les recommande sous le rapport de l'art ». Guilhermy, François (de). Itinéraire archéologique de Paris, Paris, 1855, p. 219.

65. Ces dernières ont été déposées lors du réaménagement du chœur dans les années 1960.

66. monnier.jeanpierre.free.fr/regard/Maumejean/Charles/img6.html.

67. Leniaud, Jean-Michel. Les cathédrales au XIX ${ }^{\mathrm{e}}$ siècle. Paris : éd. Economica, 1993, p. 849, n. 56.

68. L'architecte Astruc avec les peintres verriers Hirsch et Lux Fournier; Coulomb et Chauvel avec Lavergne et Pé ; Vaudremer avec Hirsch ; le Père Gally avec Villiet ; Marchand avec Didron ; Olive avec Champigneulle; Magne avec Oudinot et Gsell-Laurent, Lassus avec de Martel et Steinheil, Boileau et Lusson avec Oudinot, Gsell-Laurent, Lusson; Gau et Ballu avec Oudinot, Laurent-Gsell, Lusson et Bourdon, Maréchal, Lafaye, Thibaud et Thévenot. Voir LES EDIFICES NÉOGOTHIQUES PARISIENS ET LEURS VERRIERES - EGLISES ET CHAPELLES CATHOLIQUES, tableau infra.

69. Finance, Laurence (de). Le vitrail religieux, in FinancE, Laurence (de) et alii. Un patrimoine de lumière 1830-2000, Verrières des Hauts-de-Seine, Seine-Saint-Denis, Val-de-Marne. Paris : Monum, éd. du Patrimoine, 2003, p. 333, n. 210.

70. 13 autres ateliers seront présents en 1855 à Paris, 11 ateliers dont une majorité de parisiens, en 1862 à Londres, 30 en 1867.

71. Finance, Laurence (de). Le vitrail religieux, in Finance, Laurence (de) et alii. Un patrimoine de lumière 1830-2000, Verrières des Hauts-de-Seine, Seine-Saint-Denis, Val-de-Marne. Paris : Monum, éd. du Patrimoine, 2003, p. 73-74.

72. Pour exemples, les dessins de Gsell conservés au Cabinet des dessins du Musée Carnavalet.

73. Brisac, Catherine, Bouchon, Chantal, Vinsot, Jeanne. Les vitraux de la basilique SainteClotilde à Paris. Imprimerie alençonnaise, 1987, p. 27 et n. 30 .

74. Lasserre, Jean-Claude. La commande et les commanditaires, Revue de l'Art, $\mathrm{n}^{\circ} 72$, 1986, p. $50-54$.

75. Baronne Lagarde (101), Madame Martin Didier (102, 107), M. et Mme Georges Bonnefous (103), M. et Mme Millereau (104), M. Lamazou (105), Mme Thérèse Mellie (106).

76. Barbier de Montault, Mgr. Traité pratique...de la décoration des églises, t. I, Paris, $1^{\mathrm{e}}$ éd. $1895,3^{\mathrm{e}}$ éd. 1899, p. 57. Cité par Finance, Laurence (de). Le vitrail religieux, in Finance, Laurence (de) et alii. Un patrimoine de lumière 1830-2000, Verrières des Hauts-de-Seine, Seine-SaintDenis, Val-de-Marne. Paris : Monum, éd. du Patrimoine, 2003, p. 333, n. 226.

77. Ces ateliers ont collaboré à d'autres chantiers parisiens, de styles différents, que nous n'abordons pas dans cet article.

78. Cabezas, Hervé. La signature des vitraux français du XIX ${ }^{\mathrm{e}}$ siècle, RAMAGE, $\mathrm{n}^{\circ}$ 7, 1989, p. 77-87. 79. Didron, Adolphe-Napoléon. Création d'une manufacture de vitraux à Paris, Annales archéologiques, 1849, p. 351. Luneau, Jean-François. Modèles et cartons au XIX siècle : un enseignement pour la connaissance des pratiques anciennes ?, Vitrail et arts graphiques, 1999, p. 122,132 .

80. Il commençait par exécuter des esquisses à grandeur réelle, dessins sur papier ou calques, puis il créait le carton avec mise en plomb au trait d'encre de Chine et au crayon, indications des couleurs par $n^{\circ}$ ou initiales de la couleur. L'atelier Gaudin conserve les cartons de Steinheil Père, cotés Y6601 à Y6619 et regroupés sous la cote 03629. Voir Luneau, Jean-François. Modèles et cartons au XIX $\mathrm{X}^{\mathrm{e}}$ siècle : un enseignement pour la connaissance des pratiques anciennes ?, Vitrail 
et arts graphiques, 1999, p. 122-123, et Félix Gaudin, peintre-verrier et mosaïste (1851-1930). Clermont-Ferrand: Presses universitaires Blaise-Pascal, 2006, p. 354.

81. Le saint Denis de Lusson (baie 25) serait le portrait du cartonnier N. A. Hesse. Brisac, Catherine, Bouchon, Chantal, Vinsot, Jeanne. Les vitraux de la basilique Sainte-Clotilde à Paris . Imprimerie alençonnaise, 1987, p. 15.

82. Grodecki, Louis. Introduction, Le « Gothique » retrouvé, catalogue d'exposition, Paris, Hôtel de Sully, 1979-1980, p. 6-15.

83. Dans les Annales archéologiques qu'il dirige à partir de 1844 .

84. Cahier, Martin, Pères. Monographie de la cathédrale de Bourges, Vitraux du XIII ${ }^{\mathrm{e}}$ siècle. Paris, 1841-1844. Hucher, Eugène, Launay, Abbé. Calques des vitraux de la cathédrale du Mans... Paris, 1864. Bourassé, Abbé. Les verrières du chœur de l'église métropolitaine de Tours, 1849.

85. Fonds de dessins de Gsell au Cabinet des Arts graphiques du musée Carnavalet.

86. Didron rachète en 1868 les collections des frères Gérente. Voir Costa, Vanina. Adolphe Didron (1806-1867). Mémoire de l'École du Louvre, 1987.

87. T. IX, Paris, 1870 , p. 449-460.

88. Barbier de Montault, Mgr. Traité pratique... de la décoration des églises, t. I, Paris, $1^{\mathrm{e}}$ éd.

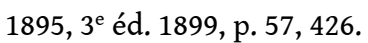

89. Finance, Laurence (de). Le vitrail religieux, in Finance, Laurence (de) et alii. Un patrimoine de lumière 1830-2000, Verrières des Hauts-de-Seine, Seine-Saint-Denis, Val-de-Marne. Paris : Monum, éd. du Patrimoine, 2003, p. 119-122. Voir sur le site www.culture.gouv.fr/culture/ inventai/patrimoine/ l'iconographie du Nouveau Testament dans Vocabulaires.

90. La Société de Marie fut fondée en 1817 par J. G. Chaminade. Callias Bey, Martine, in Finance, Laurence (de) et alii. Un patrimoine de lumière 1830-2000, Verrières des Hauts-de-Seine, Seine-Saint-Denis, Val-de-Marne. Paris : Monum, éd. du Patrimoine, 2003, p. 125-127.

91. Apocalypse, XII, I.

92. Voir sur le site www.culture.gouv.fr/culture/inventai/patrimoine/ l'iconographie des saints et des saintes dans Vocabulaires.

93. Voir sur le site www.culture.gouv.fr/culture/inventai/patrimoine/l'iconographie de l'Ancien Testament dans Vocabulaires.

94. Saint-Martin, Isabelle. Voir, savoir, croire. Catéchisme et pédagogie par l'image au XIX siècle. Paris, 2003.

95. Riou, Yves-Jean. Iconographie et attitudes religieuses, Revue de l'Art, n 72, p. 39-49.

96. Par exemple : l'iconographie de l'Immaculée Conception gravée sur la Médaille miraculeuse fut créée d'après la gravure de Pie IX distribuée aux évêques et non d'après la vision de Catherine Labouré interdite à la vénération pour défaut de preuves.

97. Le liguorisme, instillateur d'un catholicisme populaire, chaleureux et imagé, propose à la vénération « un Dieu d'amour plutôt qu'un Dieu terrible » et fait appel à la sensibilité des fidèles. 98. «Si dans les dévotions, on s'arrêtait uniquement à certains emblèmes extérieurs,... ce serait sortir de la dévotion pour tomber dans la superstition ». Boucard, Louis. Les grandes dévotions. Paris : éd. Beauchesne, 1914, p. 27.

99. Ce culte fut reconnu dès 1846 et la fête du Sacré-Cœur instituée en 1856 ; le pape Pie IX lui consacra la France en 1871 et le monde en 1875.

100. Sur la doctrine de Marie nouvelle Ève, voir Bulletins de la Société française d'Études mariales, 1951-1953. Callias Bey, Martine, in Finance, Laurence (de) et alii. Un patrimoine de lumière 1830-2000, Verrières des Hauts-de-Seine, Seine-Saint-Denis, Val-de-Marne, Paris : Monum, éd. du Patrimoine, 2003, p. 127.

101. Finance, Laurence (de). Le vitrail religieux, in Finance, Laurence (de) et alii. Un patrimoine de lumière 1830-2000, Verrières des Hauts-de-Seine, Seine-Saint-Denis, Val-de-Marne. Paris : Monum, éd. du Patrimoine, 2003, p. 115-116. 
102. Cette dévotion existait déjà au XVII ${ }^{\mathrm{e}}$ siècle ; oubliée au XVIII ${ }^{\mathrm{e}}$ siècle, elle renaît vers 1845 . Voir Lebon, H. L'Artisan de Nazareth, ou Mois de dévotion envers saint Joseph. Saint-Étienne, 1845, p. 64.

103. Callias Bey, Martine. Évolution du culte de saint Joseph, in Finance, Laurence (de). Le vitrail religieux, in Finance, Laurence (de) et alii. Un patrimoine de lumière 1830-2000, Verrières des Hauts-de-Seine, Seine-Saint-Denis, Val-de-Marne. Paris : Monum, éd. du Patrimoine, 2003, p. $127-130$.

104. Le cardinal Guibert, archevêque de Tours et futur archevêque de Paris, était membre de la communauté des Oblats de l'Immaculée Conception, dont Saint-André de l'Europe était la chapelle avant de devenir église paroissiale. Il manifesta très tôt ses choix ultramontains et encouragea le renouveau du culte de saint Martin. Finance, Laurence (de). Le vitrail religieux, in Finance, Laurence (de) et alii. Un patrimoine de lumière 1830-2000, Verrières des Hauts-deSeine, Seine-Saint-Denis, Val-de-Marne. Paris : Monum, éd. du Patrimoine, 2003, p. 338, 339, n. 460,512 .

105. Caffort, Michel. Les Nazaréens français, Théorie et pratique, Le vitrail au XIX ${ }^{\mathbf{e}}$ siècle et les ateliers manceaux, Le Mans, 1998, p. 49.

106. Au sens strict du terme, désigne une scène qui se développe sur plusieurs lancettes, sans tenir compte des meneaux.

107. Taralon, Jean. De la révolution à 1920. Le Vitrail français, 1958, p. 274.

108. Luneau, Jean-François. Vitrail archéologique, vitrail-tableau. Chronique bibliographique, Revue de l'Art, n 124, 1999, p. 67-78.

109. Pabois, Marc. Architecture et vitrail au XIX ${ }^{\mathrm{e}}$ siècle, Revue de l'Art, $\mathrm{n}^{\circ} 72,1986$, p. 61-66.

110. Cabezas, Hervé. Le sens de lecture des vitraux à séries de scènes, RAMAGE, $\mathrm{n}^{\circ} 7,1989$, p. 65-76, fig. 12; il donne pour exemple la verrière de la chapelle de la Vierge de Saint-JeanBaptiste-de-Belleville qui se lit de gauche à droite et de bas en haut.

111. Blondel, Nicole. Le Vitrail, Vocabulaire typologique et technique. Paris: Imprimerie Nationale, Ministère de la Culture, 1993, fig. 231, p. 132.

112. Antoine Lusson à Sainte-Clotilde.

113. Émile Hirsch à la chapelle de Bourbon-Condé : émail bleu sur verre bleu sur la robe de saint Jacques.

114. Charles Maréchal a utilisé à Sainte-Clotilde la gravure à l'acide sur verre rouge pour les auréoles et inscriptions, dans les grandes figures du rond-point.

115. Brisac, Catherine, Bouchon, Chantal, Vinsot, Jeanne. Les vitraux de la basilique SainteClotilde à Paris. Imprimerie alençonnaise, 1987, p. 27. Blondel, Nicole, Le Vitrail, Vocabulaire typologique et technique, p. 304.

116. L'impression sur verre peut se faire par sérigraphie, par transfert d'une gravure à l'aide d'un papier ou par empreinte à l'aide de peintures vitrifiables à travers un papier pelure de transfert, ou encore par un procédé photographique direct. (Cette technique du vitrail photo n'est pas pratiquée dans les édifices décrits dans cet article). Vincent-Petit, Flavie. Le vitrail photographique au XIX ${ }^{\mathrm{e}}$ siècle : techniques et identification, Techniques du vitrail au XIX siècle, Les dossiers de l'IPW, Namur, 2007, p. 129-142. Id. Entre innovation et industrialisation : le foisonnement des techniques mécaniques dans le vitrail au XIX ${ }^{\mathrm{e}}$ siècle, La Vie en Champagne, $\mathrm{n}$ - spécial Des sources à la lumière, juin 2008, p. 53-57.

117. Voir supra n. 81. Le saint Marc de Saint-Bernard-de-La-Chapelle est de toute évidence un portrait (autoportrait d'Oudinot?).

118. Roussel, Francis. Le peintre-verrier au XIX ${ }^{\mathrm{e}}$ siècle : un industriel ?, Revue de l'Art, $\mathrm{n}^{\circ} 72$, 1986, p. 57-60, 66.

119. ISMH 1984/04/07. Voir dans la base Mérimée : notice PA00088498.

120. MH 1939/05/24. Voir dans la baseMérimée : notice PA00088698.

121. MH 1983/03/21; Voir dans la baseMérimée : notice PA00088907. 
122. Le BECH (Bureau des édifices cultuels et historiques) qui dépend de la Mairie de Paris, travaille en liaison avec la COARCVP (Conservation des Euvres d'Art religieuses et civiles de la Ville de Paris) et le Département d'Histoire de l'Architecture et d'Archéologie ; il consacre une enveloppe de 150000 euros par an à la restauration des vitraux parisiens de toutes époques (juin 2008). PSMV : Plan de sauvegarde et de mise en valeur; PLU : Plan Local d'Urbanisme.

123. Par exemple, la chapelle Notre-Dame-des-Anges (Pères maristes) aurait pu être démolie en 1983 ; l'intervention de M. Hervé Baptiste et de Mme Colette di Matteo, a permis de la protéger rapidement (ISMH 1984/04/27) et de la sauver. Voir supra note 2.

124. À la chapelle de Bourbon-Condé dans la rose ; à la chapelle Notre-Dame-des-Anges, baies 213, 214 ; à Saint-Jean-Baptiste-de-Belleville ; à Sainte-Clotilde, baies 0, 4, 10, 12, 32 et les triplets du transept, etc.

125. À Saint-Jean-Baptiste-de-Belleville, à Sainte-Clotilde (baies 27, 28), à Saint-Eugène dans les baies de la tribune nord, à la chapelle des Sœurs de Saint-Joseph-de-Cluny (baies hautes), à SaintBernard-de-La-Chapelle (baies hautes du rond-point), à Saint-Ignace.

126. D'après une lettre de Champigneulle conservée aux Archives de la Seine (VM-32, carton 1857-1876), cité par Brisac, Catherine, Bouchon, Chantal, Vinsot, Jeanne. Les vitraux de la basilique Sainte-Clotilde à Paris. Imprimerie alençonnaise, 1987, p. 30, n. 46.

127. Didron, Adolphe Napoléon. Peinture sur verre, Annales archéologiques, 1844, p. 147-150. Il y publie, comme modèle, la reproduction du carton dessiné par Henri Gérente.

128. Thibaud, Émile. Notions historiques sur les vitraux anciens et modernes et sur l'art de la peinture vitrifiée, 1838 .

129. Lasteyrie, Ferdinand (de). La peinture sur verre au XIX ${ }^{\mathrm{e}}$ siècle, Gazette des Beaux-Arts, février 1861.

130. Magne, Lucien. L'art et les vitraux modernes, Paris, s.d. (vers 1915 ?).

131. Blondel, Nicole, Callias Bey, Martine, Chaussé, Véronique. Le vitrail archéologique : fidélité ou trahison du Moyen Âge?, Annales de Bretagne et des Pays de l’Ouest, t. 93, 1986, $n^{\circ} 4$, p. 377-381.

132. Foucart, Bruno. Les deux prétendus péchés mortels de l'architecture religieuse, Églises parisiennes du XX ${ }^{\mathrm{e}}$ siècle, Paris : Délégation Artistique de la Ville de Paris, 1996, p. 43-47.

133. Finance, Laurence (de). Le vitrail religieux, in Finance, Laurence (de) et alii. Un patrimoine de lumière 1830-2000, Verrières des Hauts-de-Seine, Seine-Saint-Denis, Val-de-Marne. Paris : Monum, éd. du Patrimoine, 2003.

134. Martine Callias Bey. À paraître en 2010 dans une collection du Corpus Vitrearum français.

\section{RÉSUMÉS}

Malgré l'intérêt porté aux œuvres d'art religieuses du XIX siècle depuis une trentaine d'années, beaucoup de vitraux religieux du XIX ${ }^{e}$ siècle ont déjà disparu à Paris ; il s'avère donc urgent de les inventorier. L'objet de l'article qui suit est la présentation des édifices catholiques parisiens de style néogothique et de leurs verrières. Ce corpus comprend 5 églises paroissiales, 19 chapelles de congrégations ou anciennes chapelles devenues paroisses, et deux bâtiments annexes. Sur 526 verrières étudiées, 286 sont ornées de figures ou de scènes dont 37 entrent dans la catégorie vitrail-tableau; les 240 autres verrières sont ornementales. 22 ateliers sont à l'origine de ces verrières, parmi les plus importants tels Didron, Lusson, Champigneulle, Hirsch, Gsell, etc. L'on 
sait que Paris a joué un rôle déterminant dans la renaissance du vitrail durant le premier tiers du $\mathrm{XIX}^{\mathrm{e}}$ siècle, grâce à la perspicacité de certains hommes de pouvoir comme le comte de Chabrol qui fut à l'origine de la « résurrection » du métier de peintre verrier avec la création du premier atelier de la Foire Saint-Laurent en 1825, grâce également à la confrontation des archéologues avec les premiers grands chantiers de restauration et le rôle décisif des architectes diocésains. L'iconographie de ces verrières reflète l'évolution du contexte religieux, de la liberté concordataire à l'explosion congrégationniste, du retour de l'autorité romaine au triomphe de l'ultramontanisme, du mouvement anticongrégationniste à la loi de Séparation de 1905. Le vitrail néogothique épouse plutôt une iconographie de tendance gallicane, teintée d'un certain «romantisme »; mais à partir de 1850, il s'ouvre à de nouvelles images et devient ce que l'on pourrait appeler un "moyen de propagande». Le vitrail néogothique marque le retour à la couleur ; l'imitation des Anciens exige une technique très maîtrisée, qui cependant s'ouvre à des procédés nouveaux comme l'impression de motifs répétitifs sur les verres de bordure ou de fond. Considérant l'éclectisme architectural du XIX ${ }^{e}$ siècle comme un style à part entière, il convient de qualifier de même ce mélange fréquent des styles, pas nécessairement cohérents, utilisés soit pour les personnages soit pour les encadrements dans les verrières dites " archéologiques » ou les « verrières-tableaux ».

Despite the interest elicited by $19^{\text {th }}$ century religious art over the past thirty years, Paris has lost much of its $19^{\text {th }}$ century religious stained glass. It was urgent to carry out an inventory of what remains. The aim of this article is to present the Catholic Gothic revival buildings in Paris and their stained glass. The corpus comprises five parish churches, 19 congregational chapels or chapel transformed into parish churches, and two other ancillary buildings. A total of 526 stained-glass works was surveyed and studied; 286 are designs with figures, 37 of these classifiable as stained-glass picture compositions. The remaining 240 works are ornamental. Behind this production, we find some 22 different stained-glass producers, amongst the most important of which are Didron, Lusson, Champigneulle, Hirsch and Gsell. Paris played a leading role in the revival of stained glass during the early years of the 19th century, thanks in part to the perspicacious inspiration of certain figures in power, such as the Prefect of Paris, the Comte de Chabrol, who was at the origins of the 'resurrection' of the skill of stained-glass painters with the 1825 creation of the works at the Foire Saint-Laurent. Further inspiration came from the first restoration work carried out on older stained-glass works, and the decisive role of diocesan architects. The iconography of these works reflects the evolution of France's religious life during the period, from the liberty of the Concordat to the Congregationist explosion, the return of Papal authority, the anti-congregationist movement, and the law of separation of church and state in 1905. Stained glass of neo-Gothic inspiration shows a Gallican tendency marked by a certain 'romanticism'. But from 1850 on, new imagery began to appear, often taking on the form of 'propaganda'. Neo-Gothic stained glass also marks a return of colour, the mastery of the art of older stained-glass artists involving considerable technical competence. The movement also involved new processes, however, such as the printing of the motifs repeated along borders or in the background. The architectural eclecticism of the $19^{\text {th }}$ century can be seen as a coherent style, but it is also a mixture of styles, not necessarily coherent, used for personages and for the framing of stained-glass works known as 'archaeological' or 'picture' compositions. 


\section{INDEX}

Mots-clés : Armoiries de Savoie, Armoiries de l'Empire, Conseil d'État, exposition Viollet-le-Duc 1980, colloque international Viollet-le-Duc 1980, Laurence de Finance, Lucien Magne, Ferdinand de Lasteyrie, Louis Grodecki, Élisabeth Pillet, Jean-François Luneau, Françoise Gatouillat, Hervé Cabezas, Patrick Bracco, Nicole Blondel, Vanina Costa, Pierre-Marie Auzas, Chantal Bouchon, Catherine Brisac, Jean-Michel Leniaud, Bruno Foucart, Union syndicale des architectes français, Recensement des vitraux anciens de la France, Corpus Vitrearum de la France, Vitrail français, Un patrimoine de lumière, Guide des sources de l'histoire des congrégations féminines françaises de vie active, cellule Vitrail de l'Inventaire Général, Association pour l'étude du XIXe siècle français, GRIMCO, Dictionnaire raisonné de l'Architecture, Bourges-Vitraux du XIIIe siècle, Traité sur les Divers Arts, Voyages pittoresques et romantiques dans l'ancienne France, Monuments de France, Rapport sur la peinture sur verre, Alexandre Brongniart, Bontemps, Service des monuments historiques, Commission des monuments historiques Service des édifices diocésains, architectes diocésains, Commission des arts et édifices religieux, Comité des inspecteurs généraux des édifices diocésains, Comité historique des arts et monuments, Société pour la conservation des monuments, Société française d'archéologie, musée des Monuments français, Société artistique de peinture sur verre, Catherine Labouré, Marguerite-Marie Alacoque, vitraux légendaires à médaillons, vitraux à personnages sous arcade, verrières-tableaux, Ludovic Vitet, Prosper Mérimée, Alexandre Lenoir, Alexandre de Laborde, baron Taylor, Charles Nodier, comte Charles de l'Escalopier, Pierre Le Vieil, Henri Chabin, Louis-Charles-Marie Champigneulle, Tournel, Félix Gaudin, Daumont-Tournel, Breton, Charles Maréchal, Henri Marchand, Paul Courcoux, Édouard Bérard, Édouard-Amédée Didron, Carl Geyling, Prosper Lafaye, Charles Lévêque, Auguste de Martel, Jules-Pierre Mauméjean, Pierre Petit-Gérard, Étienne-Hormidès Thevenot, Joseph Villiet, Lux Fournier, Louis Steinheil, Alexandre Hesse, Louis Lamothe, Benoît Chancel, Amaury-Duval, Paul Jourdy, Nicolas-Auguste Galimard, Théodore Ballu, Gérard-Seguin, Henri Chailleux, Luc-Olivier Merson, Jean-Paul Laurens, François-Emile Ehrmann, Eugène Grasset, Jean Bazaine, Médaille miraculeuse, Jean Taralon, restauration de Notre-Dame de Paris, restauration de la Sainte-Chapelle, Georges-Claudius Lavergne, Adolphe-Napoléon Didron dit l'Aîné, Jean-Baptiste Lassus, Eugène Viollet-le-Duc, François Debret, Louis-Auguste Boileau, Jules Astruc, Emile Vaudremer, Anatole de Baudot, Abel de Pujol, Warren-White, Antoine Lusson, Alfred Gérente, Fialeix, Eugène-Stanislas Oudinot, Jean-Gaspard-Jules Gsell, Charles-Émile Hirsch, François Pé, Sainte-Clotilde, beffroi de Saint-Germain-l'Auxerrois, Saint-Germain-l'Auxerrois, sacristie de Notre-Dame-de-Paris, Notre-Dame-de-Paris, Notre-Dame du Liban, chapelle NotreDame-des-Anges, chapelle Notre-Dame-du-Bon-Secours, rationalisme, éclectisme, églises parisiennes, historicisme, néoroman, néogothique, comte de Chabrol, Mgr Affre, Pie X, SaintPierre-de-Chaillot, loi de Séparation, saint Vincent de Paul, Pie IX, Concordat, ultramontanisme, gallicanisme, chapelle de l'Accueil-Louise-de-Marillac, chapelle Saint-Ignace, chapelle de l'ancien hôtel de Bourbon-Condé, hôtel de Bourbon-Condé, chapelle de Jésus-Enfant, Saint-André de l'Europe, chapelle des Sœurs du Bon-Secours-de-Troyes, Saint-Eugène, chapelle des Jeunes de Saint-Vincent-de-Paul, Saint-Joseph-Artisan, Sainte-Rosalie, Saint-Hippolyte, chapelle SainteJeanne-d'Arc, chapelle des Sœurs de Saint-Joseph-de-Cluny, chapelle de l'Orphelinat SaintCharles, chapelle Sainte-Marie-de-la-Famille, chapelle Notre-Dame-du-Saint-Sacrement, chapelle Sainte-Thérèse-de-l'Enfant-Jésus, Saint-Bernard-de-la-Chapelle, Notre-Dame-du-Bon-Conseil, Saint-Jean-Baptiste-de-Belleville, chapelle de l'École Sainte-Geneviève des Jésuites, École SainteGeneviève des Jésuites, chapelle des Filles de la Charité, chapelle de la Compagnie de Jésus, SaintIgnace, chapelle des Sœurs Sainte-Marie-de-la-Famille, chapelle des Orphelins d'Auteuil, chapelle de la Mère-de-Dieu, Notre-Dame-du-Perpétuel-Secours, Saint-Séverin, Sœurs de Saint-Joseph-de- 
Clun, Sœurs Servantes du Saint-Sacrement, Filles de la Charité, Lazaristes, Sœurs du Bon-Secours, Sœurs de Notre-Dame-des-Anges, Sœurs de Sainte-Marie-de-la-Famille, Sœurs du Bon-Secoursde-Troyes, Franciscaines missionnaires de Marie, Marianistes, Maristes des écoles, Frères des écoles chrétiennes, Salésiens de Don Bosco, Rédemptoristes, Oblats de Marie Immaculée, Maristes missionnaires, Dames du Sacré-Cœur, Dames de l'Assomption, École des Carmes, Mgr Sibour, Anne-Marie Jahouvey, Père Eymard, Louise de Marillac, Joséphine Potel, Mgr de Quélen, Père Bayle, Marie de la Passion, Hélène de Chappotin, saint Marcellin Champagnat, Guillaume Joseph Chaminade, saint Jean Bosco, Alphonse de Liguori, Mgr Dupanloup, saint Jean-Baptiste de la Salle, Mgr de Mazenod, Père Colin, abbé Godard, abbé Migne, abbé Coquand, moine Théophile, sœur Rosalie Rendu, Mgr Barbier de Montault, Père Cahier, Père Martin, pape Léon XIII, pape Sixte IV, cardinal Hippolyte Guibert, Félix Le Gentil, famille Lebaudy, comte de Chambrun, famille de Saint-Remy, famille de Pontoipontcarre, famille Dulac de Fugères, églises néogothiques, chapelles néogothiques, églises parisiennes du XIXe siècle, vitraux parisiens du XIXe siècle, chapelles parisiennes, chapelles parisiennes du XIXe siècle, enseignement au XIXe siècle, style troubadour, vitrail archéologique, iconographie religieuse du XIXe siècle, renouvellement de l'iconographie religieuse, thèmes christiques, thèmes mariaux, liguorisme, dogme de l'Immaculée Conception, Syllabus, dogme de l'infaillibilité pontificale, dogme de la primauté universelle de droit divin du pape, concile Vatican I, anticléricalisme, statut des congrégations religieuses, congrégations autorisées, congrégations missionnaires, congrégations enseignantes, expulsion de congrégations, Émile Combes, loi Falloux 1850, loi Laboulaye 1875, loi Ferry 1882, loi Goblet 1886, archiconfrérie du Sacré-Cœur-de-Marie, loi Guizot 1833, Association de la Sainte-Famille, CEuvre des chapelles de secours

Keywords : Savoy coat of arms, Imperial coat of arms, Viollet-le-Duc exhibition 1980, Viollet-leDuc conference 1980, Inventory of French stained glass, French stained glass, heritage of light, Guide to the sources on the history of French women's congregations, Stained glass cell of the French General Inventory, Association for the study of the 19th century in France, BourgesVitraux of the 13th century, French monuments, Report on stained-glass painting, Historic Monuments service, Diocesan architects, Legendary stained glass with medallions, Stained glass with figures beneath an arcade, Picture stained glass, Restoration of Notre-Dame-de-Paris, Restoration of the Sainte Chapelle, Belfry of Saint-Germain-l'Auxerrois, Sacristy of Notre-Damede-Paris, Neo-Gothic churches, Neo-Gothic chapels, Parisian churches, 19th century Parisian churches, 19th century stained glass, Parisian chapels, 19 th century Parisian chapels, 19 th century teaching, Eclecticism, Neo-Gothic, Neo-Romanesque, Troubadour style, Rationalism, Historicism, Archaeological stained glass, Religious iconography of the 19th century, Renewal of religious iconography, Christic themes, Virgin Mary themes, Gallicanism, Ultramontanism, Liguorism, Dogma of the Immaculate Conception, Dogma of papal infallibility, Dogma of the universal primacy of the Pope's divine right, Vatican I council, Anticlericalism, Separation of church and state, Statutes of religious congregations, Authorised congregations, Missionary congregations, Teaching congregations, Expulsion of the congregations, Falloux law of 1850, Laboulaye law of 1875, Ferry law of 1882, Goblet law of 1886, Archiconfrérie of Sacré-Cœur-deMarie, Guizot law of 1833, Association of the Holy Family, CEuvre of the Chapelles de secours

\section{AUTEUR}

\section{MARTINE CALLIAS BEY}

Chercheur, Centre André Chastel. Martine.Callias_Bey@paris-sorbonne.fr 